\title{
A REVIEW OF VARIOUS POUR POINT DEPRESSANTS USED FOR FLOW ASSURANCE IN OIL INDUSTRIES
}

\author{
Gaurav Himanta Khaklari \\ Department of Petroleum Technology, \\ Dibrugarh University
}

\begin{abstract}
Crude oil needs to be transported from oil wells to refinery and storage facilities in one form or another to ultimately become end use products. After the successful extraction of oil from the ground it is mostly transported through pipelines where the crude oil experiences various changes in its physical and chemical properties. These rheological changes may cause numerous flow assurance problems such as wax and paraffin deposition which ultimately restricts the flow of oil. Chemical additives such as Pour Point depressants (PPDs) are used in this case for the efficient transportation of crude oil by lowering the Wax Deposition Temperature (WAT). Hence, in order to enhance the knowledge about PPDs, the mechanism of various types of Pour Point Depressant for aiding the flow of crude oil while transportation were discussed in this paper.
\end{abstract}

Keywords: Pour point Depressant (PPDs), Wax appearance temperature (WAT), Flow improver (FI)

\section{INTRODUCTION}

One of the major flow assurance problems in the oil industry is the formation of wax during the transportation and production of crude oil [Thevaruban et al. (2020)]. During cold weather conditions these crude oil production encounters numerous operational problems due to obstruction in flow pipes or production lines which is caused due to paraffin formation and its blockage. As temperature decreases crude oil becomes more viscous and once it goes below the pour point temperature it can no longer flow or be pumped [A.M. et al.(2009)]. The temperature below which the liquid loses its flow characteristics is known as the pour point temperature. In such situations, some sort of experimental chemicals, namely Pour Point Depressants (PPDs)/ Flow improvers (FIs) are used which helps in lowering the pour point temperature and facilitate the flow of crude oil by lowering the wax appearance temperature(WAT) of the oil [ Akanksha et al.(2019)].

In this review paper, some of these pour point depressants are discussed according to their needs of situation and the type of crude that is being transported.

\author{
Prasenjit Talukdar \\ Department of Petroleum Engineering, \\ Dibrugarh University
}

\section{DISCUSSION}

Table 1: List of PPDs discussed

\begin{tabular}{|c|c|}
\hline Sl No. & PPDs \\
\hline 2.1 & N-alkyl-2-aminopyridinum \\
\hline 2.2 & $\begin{array}{l}\text { Polymeric Additives based on Vinyl Acetate } \\
\text { Copolymers }\end{array}$ \\
\hline 2.3 & $\begin{array}{l}\text { Oleic acid based or maleic anhydride based } \\
\text { polymeric additives }\end{array}$ \\
\hline 2.4 & Oil-based and water-based viscosity reducer \\
\hline 2.5 & Aromatic Polyisobutylene Succinimides \\
\hline 2.6 & Styrene and vinyl acetate (SVA) copolymers \\
\hline 2.7 & Bio-based flow improver \\
\hline 2.8 & Hexatriethanolamine mono oleate \\
\hline 2.9 & $\begin{array}{l}\text { Aminated copolymer and ethylene-vinyl } \\
\text { acetate copolymers (EVA) }\end{array}$ \\
\hline 2.10 & Modified Maleic Anhydride Co-polymers \\
\hline 2.11 & Three Sets of Surfactants \\
\hline 2.12 & PEAA graft co-polymer (PEAA-g- VA) \\
\hline 2.13 & Paraffin inhibitor from vegetable oil \\
\hline 2.14 & $\begin{array}{l}\text { Anhydride and esters of n-alkyl alcohols based } \\
\text { Polymeric Additives }\end{array}$ \\
\hline 2.15 & Poly-Hydrazide \\
\hline 2.16 & Triethanolamine (TEA) \\
\hline 2.17 & $\begin{array}{l}\text { Ethylene Acrylic Alkyl Ester Copolymer Wax } \\
\text { Dispersants }\end{array}$ \\
\hline 2.18 & HeteroAtoms compounds \\
\hline 2.19 & Multifunction Co-polymer \\
\hline 2.20 & Polymeric pour point depressants \\
\hline 2.21 & Emulsified Acrylate Polymer \\
\hline 2.22 & $\begin{array}{l}\text { Copolymer Solubilized in Organic Solvent } \\
\text { with an Aromatic hydrocarbon }\end{array}$ \\
\hline 2.23 & Oleic acid based polymeric flow improvers \\
\hline
\end{tabular}


International Journal of Engineering Applied Sciences and Technology, 2021

Vol. 6, Issue 1, ISSN No. 2455-2143, Pages 335-352

Published Online May 2021 in IJEAST (http://www.ijeast.com)

\begin{tabular}{|c|c|}
\hline 2.24 & $\begin{array}{l}\text { Comb-type polymeric acid alkylamide-co- } \alpha \text { - } \\
\text { olefin) }\end{array}$ \\
\hline 2.25 & Spirocompound as Clean Viscosity-Reducer \\
\hline 2.26 & $\begin{array}{l}\text { Alkyl Fumarate-Vinyl Acetate Copolymers in } \\
\text { Combination with Alkyl Acrylates }\end{array}$ \\
\hline 2.27 & Low molecular weight polybehenyl acrylate \\
\hline 2.28 & Novel Pour Point Depressants \\
\hline 2.29 & Methacrylate Based Polymeric Additives \\
\hline 2.30 & Polymeric structures as cold flow improvers \\
\hline 2.31 & $\begin{array}{l}\text { Phthalic anhydride-polyethylene glycol ester } \\
\text { (PAP) }\end{array}$ \\
\hline 2.32 & PE-b-PEP deblock copolymers \\
\hline 2.33 & $\begin{array}{l}\text { Modulating Long-Chain } \\
\text { Crystallization with Comb Polymers, (by X- } \\
\text { ray Diffraction) }\end{array}$ \\
\hline 2.34 & $\begin{array}{l}\text { Polymeric Additives Based on Vinyal Acetate } \\
\text { Copolymers }\end{array}$ \\
\hline 2.35 & $\begin{array}{l}\text { Polymethyl Methacrylate- Graphene Oxide } \\
\text { Nano-Hybrid Polymers }\end{array}$ \\
\hline 2.36 & Hydrophobically Modified Polyampholyte \\
\hline 2.37 & Four sets of copolymeric additives \\
\hline 2.38 & $\begin{array}{l}\text { Synthesized polymeric pour point depressant } \\
\text { from olive oil }\end{array}$ \\
\hline 2.39 & $\begin{array}{l}\text { Comb-type co-polymers of poly(maleic } \\
\text { anhydride-co- } \alpha \text {-olefin-co-styene) (MASC) }\end{array}$ \\
\hline 2.40 & $\begin{array}{l}\text { Maleic anhydrade copolymers (MAC) and } \\
\text { poly(ethylene butene) polymers }\end{array}$ \\
\hline 2.41 & Vinyl acetate-behenyl fumarate copolymer \\
\hline 2.42 & Madhuca longifolia \\
\hline 2.43 & Esters of styrene-maleic anhydride copolymers \\
\hline 2.44 & $\begin{array}{l}\text { Polymer of <aleic anhydride } \\
\text { Pentacrythritol stearic diacetate (PSM) }\end{array}$ \\
\hline 2.45 & $\begin{array}{l}\text { Three phthalimide and three succinimide } \\
\text { copolymers }\end{array}$ \\
\hline 2.46 & Poly(n-alkyl itaconate-co-vinyl acetate) \\
\hline 2.47 & Poly(styrene-co-octadecyl maleimide) \\
\hline 2.48 & $\begin{array}{l}\text { Biosurfactant from Pseudomonas putida and } \\
\text { Halomous xianhensis (Bacteria) }\end{array}$ \\
\hline 2.49 & $\begin{array}{l}\text { Long chain acrylic esters polymers with polar } \\
\text { monomers }\end{array}$ \\
\hline 2.50 & Natural seed oil to act as flow improver \\
\hline 2.51 & BEM series of PPDs \\
\hline 2.52 & Terpolymer \\
\hline 2.53 & Polyacrylate \\
\hline 2.54 & Aqueous surfactant \\
\hline 2.55 & Graphene-Based Noval Nanocomposite PPDs \\
\hline
\end{tabular}

\subsection{N-alkyl-2-aminopyridinum oligomers}

In cold environments waxy crude oils always suffer serious problems during transportation and storage. This is due to large amounts of paraffin wax in the crude oil which impede the flow of crude oil due to wax precipitation [P. Kriz et al. (2005)].

Eid et al.(2018) discusses three compounds namely $\mathrm{N}$-decyl-(C10P), N-dodecyl-(C12P) and N-cetyl-2aminopyridinum $(\mathrm{C} 16 \mathrm{P})$ oligomers which were synthesized by oxidative polymerization of $\mathrm{N}$-decyl-(C10), N-dodecyl-(C12) and $\mathrm{N}$ cetyl-2-aminopyridinium vromide monomers each separately in aqueous acid medium.

The raw materials namely 2-Aminopyridine, decyl bromide, dodecul bromide, and cetyl bromide were obtained from Sigma Aldrich Chemical Co. Concentrated hydrochloric acid and sodium hydroxide were chemically pure grade products provided by Prolabo-Chemical Co. (U.K.). Ammonium persulphate (APS), methanol and DMF were products of Aldrich chemical company (Germany). 30\% aqueous solution of sodium hypochlorite $(\mathrm{NaOCl})$ was supplied by El-Nasr Chemical Co. (Egypt). Twice distilled water used as a medium for all the polymerization reactions. For the quantitative understanding of the material properties Density functional theory (DFT) was carried out and found out that the oligomeriztion precede via open ring reaction. Further experiments were done which included characterization by using FTIR and H NMR spectroscopy, XRD and SEM to know the morphology of the oligomers, thermogravimetric analysis (TGA), measurement of the surface tension at different concentrations and temperatures. The efficiency of the synthesized oligomers in depressing the pour point of the crude oil was found out which showed that these oligomers were highly efficient to reduce the pour point of crude oil [Eid et al. (2018)].

\subsection{Polymeric Additives Based on Vinyl Acetate Copolymers}

At low temperatures, deposition of paraffin which is formed during production and transportation of light crude oil and natural gases and condensates is one of the main problems that affect the productivity of oil [R. Hoffmann et al.(2013)]. The above PPD/FI was used in Egyptian waxy crude oils. Waxy crude oil contains different amount of paraffin wax depending on the field and area of deposition. The constituent of crude oil wax deposition occurs due to cooling of temperature during the transportation and storage [A.E. Erceg et al. (2008)]. In this study, maleic amhydride ester-co-vinyl acetate copolymers with feed ratio along with different alkyl ester were synthesised. The raw materials, Vinyl acetate, maleic anhydride, dodecyl alcohol (DA), stearyl alcohol (SA), behenyl alcohol (BA), benzoyl peroxide (BP), and P-toluene sulfonic acid monohydrate (PTSA) were bought as analytical grade from Aldrich Chemicals Co., Germany. Benzene, dimethylformamide (DMF), and xylene were delivered from Adweic Chemicals Co., Egypt. Egyptian waxy crude oil (Norpetco, Egypt) was delivered without treatment from Fardous field. The experimental procedure included selection 
of materials, copolymerization, esterification, characterization and Evaluation test. Maleic anhydride-vinyl acetate copolymer was prepared by copolymerizing vinyl acetate (VA) and maleic anhydride (MA).

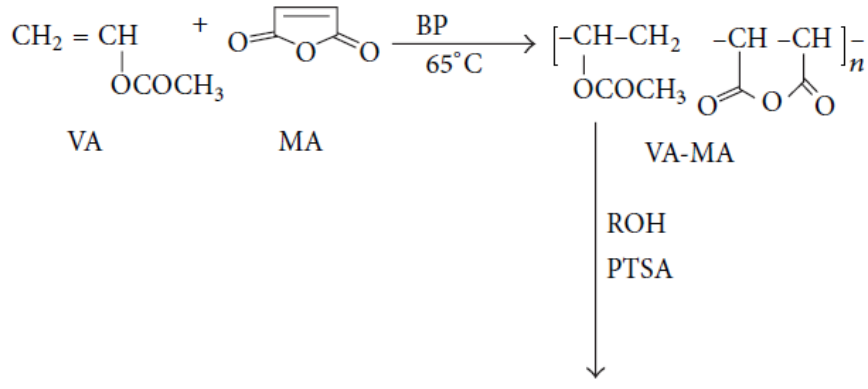

$$
\begin{aligned}
& {\left[\begin{array}{ccc}
-\mathrm{CH}-\mathrm{CH}_{2} & -\mathrm{CH}- & \mathrm{CH}- \\
\mid & \mid & \mid \\
\mathrm{OCOCH}_{3} & \mathrm{COOR} & \mathrm{COOR}
\end{array}\right]_{n}} \\
& \begin{array}{ll}
\mathrm{R}=\mathrm{C}_{12} \mathrm{H}_{25} & \text { VADM } \\
\mathrm{R}=\mathrm{C}_{18} \mathrm{H}_{37} & \text { VASM } \\
\mathrm{R}=\mathrm{C}_{22} \mathrm{H}_{45} & \text { VABM }
\end{array}
\end{aligned}
$$

Synthesis of VA-MA ester copolymers.

Figure 1: Synthesis of VA-MA ester copolymers. [Prabha et al.(2020)]

Characterization of these polymeric materials was carried out with the help of FTIR, HNMR and GPC. The performance of these pour point depressants for Egyptian waxy crude was evaluated by measuring the rheological properties such as viscosity, yield stress etc. In order to decrease the pour point temperature, and to improve the rheological characteristics of crude oils, the effective concentration of PPD to inhibit the wax deposition was found to be 100-10000 ppm. At the end it was observed that stearyl maleate-vinyl acetate copolymer with 1:2 feed ratio shows best efficiency as pour point depressant even at low concentration with octadecyl maleatevinyl acetate copolymers with 2:1 feed ratio. [Ayman M. Atta et al. (2015)]

\subsection{Oleic acid based or maleic anhydride based polymeric additives}

Prabha et al. (2020) synthesized some PPDs which included oleic acid based or maleic anhydride based polymeric additives through esterifcation and Friedel Craft Alkylation. The experiment was done on crude oil of the Limbodra, Nada, Langhnaj Akholjuni of Gujarat region. The results were examined through SARA Analysis, Fourier Transform Infrared Spectroscopy (FTIR), and Gel Permeation Chromatography (GPC). Various Synthesized PPD were tested and experimented with the crude oils of different region and sector and which helped reduced the pour point of the crude oil by $3-21^{\circ} \mathrm{C}$. The results of this test for the different regions and sectors were able to reduce the pour point of the crude by $6^{0}$ C. [Mrs. Prabha et al. (2020)]

\subsection{Oil-based and water based viscosity reducers}

The production of crude oil can be basically divided into three stages: formation drive, wellbore lifting and pipeline transportation. Also the crude oil can be divided into conventional oil, heavy oil, extra heavy oil and bitumen on the basis of their viscosity. [Li et al. (1990)] In china the conventional crude oil has high wax content, high pour point and viscosity which results in poor flow.[Wang.(1995)]. Therefore, Oil-based and water-based viscosity reducers in both low-viscosity and high-viscosity heavy oil wells were used as flow improvers in long distance pipeline transportation in China. The oil-based viscosity reducers consist of macromolecule polymers with strong polar groups which have good viscosity-reducing effect for heavy oil. For water-based viscosity reducer it is a composition of surfactants and emulsion stabilizers. The water based viscosity reducer is able to reduce the viscosity of heavy oil by $90 \%$. Both this PPDs are used to lift the extra heavy oil from the wellbore. [Fusheng et al.(2018)]

\subsection{Aromatic Polyisobutylene Succinimides}

As the production of conventional oils is decreasing, the uses of heavy and extra-heavy crude oil are becoming more popular day by day. Along with this trend, the challenges in flow assurance are also increasing. The oil field located in Latin America, especially, Colombia, Venezuela and Mexico are facing problems in the development of these heavy oils[Laura et al. (2011)].In this research work four aromatic polyisssobutylene succinimades were utilized as viscosity reducers for heavy crude and extra heavy crude oils of Mexico.Because of the asphaltenic character these aromatic heads are capable of interacting with asphaltene aggregates by $\pi-\pi$ stacking, hydrogen-bond formation, and acid-base interactions. Evaluation of Asphaltene dispersionaggregate inhibition and asphaltene disaggregation effects were carried out as promoters of the viscosity reduction effect in asphaltenic crude oils. Here the asphaltene disaggregation was seen to be dominant. The chemical compounds showed fair results as asphaltene aggregation inhibitors and dispersants as well as viscosity reducers. Both these experiments were studied by theoretical DFT calculations. These compounds have shown to reduce the viscosity by changing the morphology of asphaltene aggregates, so that when they are mixed with the reservoir crude the problems such as asphaltene precipitation and pipe clogging are avoided. [Tomás et al (2013)]

\subsection{Styrene and vinyl acetate (SVA) copolymers}

Crude oil pipelines in deep seawater causes serious operational problems as it is constantly under very low temperatures conditions, provoking the crystallization of wax and paraffins into solid deposits. Styrene (S), n-butyl acrylate $(\mathrm{BuA})$, and vinyl acetate (VA) monomers were used to derive a series of copolymers by emulsion polymerization to improve the physical properties of Mexican crude oils (MCOs). Characterization of these copolymers was done by using Fourier transform infaraed (FTIR) spectroscopy, size exclusion chromatography (SEC), and thermogravimetric 
analysis (TGA). It was found that styrene and vinyl acetate (SVA) copolymers have the best results as pour point depressant. Crude oils above $35^{\circ} \mathrm{C}$ have shown decreased apparent viscosity for both light and heavy crude oils after the use of these copolymers [Laura et al. (2008)].

\subsection{Bio-based flow improver}

In deep-water developments, wax precipitation and deposition is a major flow assurance hazard in the production and transportation of waxy crude oil.[Sarica and Panacharoensawad (2012)] Wax precipitation increases oil viscosity and with the added risk of gelation formation it changes the oil flow properties[ Odutola and Idemili(2020)].The use of pour point depressants and flow improvers to mitigate the wax formation will help improve flow properties and reduce the need for expensive remedial operations like pigging.[Wang et al.(2015)].Research aiming for the development of low cost, bio-based, additives for crude oil flow improvement is a growing interest in the oilfield industries.[Ragunathan et al.(2020)] In this study, with the help of diethanolamine and sulfuric acid, natural cashew nut shell were modified to form sulfonated cashew nut shell liquid esteramine (CNX).

With the presence of the additives, the average Feret diameter, aspect ratio and boundary fractal dimension of wax crystals were decreased, while crystal circularity and solidity increased as smaller, rounder and more regular crystals with smoother, even surfaces were formed. This compound was used in waxy crude, which resulted in depressing the pour point and changing the morphology and micro structure of wax crystal which ultimately improved the flow properties of waxy crude oil. [William et al. (2021)]

\subsection{Hexatriethanolamine mono oleate}

The problems during the production, separation, transportation and refining of crude oils occurs due to the deposition of waxy crude oil with high pour point and viscosity.[ Sharma et al.(2012)] The deposition of wax may reduce the effective flow rate and lead to complete blockage of the pipelines. The stage at which the temperature decreases to a point where the crude oil ceases to flow is called the pour point. [Mahto et al.(2010)]. Shivanjali et al. (2014) studied the effect of flow improvers on the rheological and microscopic properties of waxy crude oil of the western oil field of India and a flow improver named hexatriethanolamine mono oleate was synthesized in the laboratory.

$$
\begin{gathered}
\mathrm{H}\left[-\mathrm{OCH}_{2} \mathrm{CH}_{2} \mathrm{NCH}_{2} \mathrm{CH}_{2} \mathrm{OHCH}_{2} \mathrm{CH}_{2}-\right]_{6}+\left[\mathrm{CH}_{3}\left(\mathrm{CH}_{2}\right)_{7} \mathrm{CH}=\mathrm{CH}=\mathrm{CH}\left(\mathrm{CH}_{2}\right)_{7} \mathrm{COO}\right] \\
\left.\stackrel{\text { ole acid }}{\longrightarrow}\left[\mathrm{CH}_{3}\left(\mathrm{CH}_{2}\right)_{7} \mathrm{CH}=\mathrm{CH}\left(\mathrm{CH}_{2}\right)_{7} \mathrm{COO}\right] \mathrm{CH}_{2} \mathrm{CH}_{2} \mathrm{NCH}_{2} \mathrm{CH}_{2} \mathrm{OHCH}_{2} \mathrm{CH}_{2} \mathrm{O}\right]_{6} \\
\text { hexatriethanolamine mono oleate }
\end{gathered}
$$

Figure 2: Hexatriethanolamine mono oleate

During the study it was found that the crude oil under present study is waxy in nature, and it is predominantly rich in saturate fractions. While the shear rate has a noticeable effect, with regard to decreasing the viscosity, especially at low temperatures, and the viscosity is more stable at higher shear rates. Also the efficiency of flow improvers seems to increases as their concentration in the solution increases. Here the microstructures of crude oils is influenced strongly by both temperature and cooling rate. When this compound was used and compared with a commercial flow improver it was found that, the synthesized flow improver has shown better flow performance for the crude oil. [Shivanjali et al.(2014)]

\subsection{Aminated copolymer and ethylene-vinyl acetate copolymers (EVA)}

Pour Point Depressent for Shengli crude oil was prepared by mixing the aminated copolymer and the composite commercial ethylene-vinyl acetate copolymers (EVA) in fixed proportion. Amination of tepolymer copolymerized with mono octadecyl acrylate, maleic anhydride, and vinyl acetate were used to synthesize the aminated copolymer. Characterization was done with the help of Fourier transform (FTIR) spectroscopy, H nuclear magnetic resonance (H NMR) and gel permeation chromatography (GPC). New agglomerates of asphaltene-PPD resin were formed after it analysis by FTIR, differential scanning calorimetry (DSC), and cross-polarized light microscopy. The prepared pour point depressant (PPD) was used in the Shengli high-pour-point oil at a dosage of 400 ppm which resulted in decreasing the pour point by $11^{\circ} \mathrm{C}$. An impact on the process of wax crystallization in the crude oil was due to the interaction between resin and asphaltene. The new agglomerates was formed by the PPD, asphaltene, and resin merged together. This compound was seen to reduce the pourpoint of the crude oil greatly by changing the wax crystallization process.[ Long at et.(2012)]

\subsection{Modified Maleic Anhydride Co-polymers}

Maleic anhydride co-polyemer and its derivatives with different polar and aromatic pendant chains were designed and synthesized. Four polymeric additives were made which showed good efficiency as flow improvers in Changqing (CQ) crude. Characterization of the compounds was done by Fourier transform infrared (FTIR) spectroscopy and gel permeation chromatography (GPC). After the addition of these compounds, the pour point was reduced and rheological parameters enhanced. The results of this experiment shows that all four polymeric additives having good efficiency as PPDs and flow improvers for the CQ crude oil with low asphaltene content. Also the performance of flow improvers can be optimized through proper polymer design. Here the polymeric derivative with $\mathrm{N}$-containing short branches along the polymer backbone showed better results than the introduction of short-chain esters. However, the best performance was shown by polymer containing aromatic units which depress the pour point by $19^{\circ} \mathrm{C}$ along with yield stress and viscosity reduction.[Yumin et al.(2012)]

\subsection{Three Sets of Surfactants}

Use of modern effective solutions is a necessity for better crude oil transportation through pipeline. 
In this study, three set of surfactants additives (considering them as $\mathrm{A}, \mathrm{P}$ and $\mathrm{C}$ ) which are synthesized by esterfication of polyethylene glycol with adibic acid, phythalic acid and citric acid then re-esterfication of polyethylene glycol adipate, phythalate and citrate with triethaolamine. These additives were found to gives good surface properties; good pour point depression properties for fuel oil. Here, surfactant $\mathrm{A}$ additive is more efficient (as pour point $\square$ pp 2000ppm $=12{ }^{\circ} \mathrm{C}$ ) than surfactant $\mathrm{P}$ and $\mathrm{C}$, $\left(\square\right.$ pp 2000ppm $=9{ }^{\circ} \mathrm{C}$ and $\left.6{ }^{\circ} \mathrm{C}\right)$. The prepared PPD, surfactant A was blended with both commercial flow improvers (CFI) and natural wax dispersant (NWD) to show exhibited good compatibility as (500:1000:500), $\square$ pp 2000ppm $=-21$ oC. [F.M.Ghuiba et al.(2014)].

\subsection{PEAA graft co-polymer (PEAA- g-VA)}

Crude oil contains paraffins, aromatic hydrocarbons, resins and asphaltenes which is a very complex mixture. [Venkatesan et al.(2003)] When the temperature is high crude oil behaves as Newtonian fluids and the viscosity is low, but in pipelines due to low temperature this property cannot hold as the solubility of long chain paraffins and asphaltenes decrease remarkably, so the viscosity increases, flow decreases and pipelines get blocked [El-Gamal et al. (1997)]. Here, Poly ethylene acrylic acid derivatives were prepared by reacting PEAA with alchohols and amines then grafted with vinyl acetate in the presence of PTSA (P-Toluene sulfunic acid Monohydrate) as catalyst and xylene as solvent to produce graft co-polymers. The compound was characterized and purified by FTIR and HNMR. It was seen that better performance of the additive was shown for a given copolymer composition by increasing the length of the alkyl group. While the best performance as pour point depressant was shown by the PEAA-g- VA with amine, using optimum dosage of $3000 \mathrm{ppm}$ for the Khalda crude oils. Even at low concentrations of about $500 \mathrm{ppm}$ the values of the plastic viscosity $(\mathrm{mPaS})$ and yield values $(\mathrm{Pa})$ are found to decrease by the addition of PEAA graft co-polymeric additives. After its study it was found that the influence of PEAA graft copolymer as flow improver lead to a large reduction in pour point temperature for samples of Khalda Petroleum Co. (KhPC) crude oils [H.I.Al-Shafey et al.(2014)].

\subsection{Paraffin inhibitor from vegetable oil}

Pipeline transportation has become complex and major difficulty due to high viscosity of crude oil, so efficient and economic ways for dealing with this problem has to be invented. [E.M. Newberry (1984), C.R.Price(1971)]. By using soybean oil and canola oil as raw material a new kind of novel paraffin inhibitor namely polyaminoamide (PAA) was made through the process of aminolysis and polycondensation. The structure of PAA was modified by introducing hetero atoms (N) into the main chain to enhance the polar and reduce thermo stability of the main chain for the active $\mathrm{C}-\mathrm{N}$ bonds compared with C-C bonds.

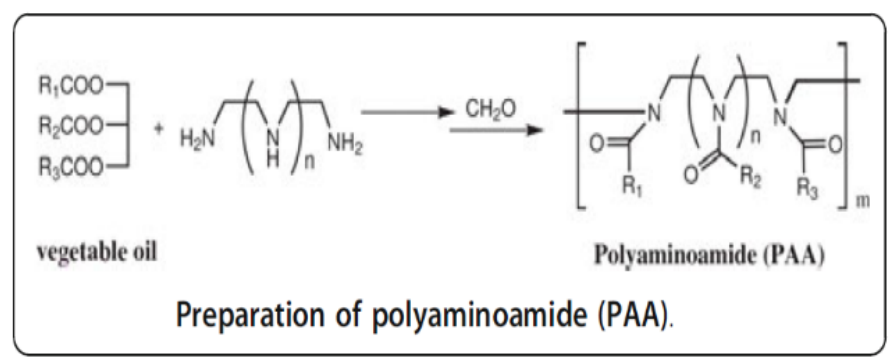

Figure 3: Preparation of polyaminoamide (PPA) [Gang et al.(2011)]

Here the PAAs as paraffin inhibitors and the paraffin crystal morphology was tested and analysized to investigate the interaction between PAA and paraffin crystal. After studying the properties of the PAAs as paraffin inhibitor, it was concluded that several PAA samples are suitable for paraffin inhibition, and among which polyethylene polyamine is the most effective one. [Gang et al. (2011)]

\subsection{Anhydride and esters of n-alkyl alcohols based Polymeric Additives}

The efficiency of flow improvers and pour point depressants can be based various factors such as the number of pendant alkyl side chains and the length and distance between them, the solubility of the additives in crude oil (average molecular weight dependent), for copolymer additives monomer to monomer ratio consideration, amorphous and crystalline parts, physical and chemical stability. [Misra et al.(1995), Bothakur et al.(1995)]. Son et al.(1993) describes that most of these requirements are satisfied by Maleic anhydride co-polymers . Synthesis of copolymers of maleic anhydride and esters of nalkyl alcohols with oleic acid and methacrylic acid was carried out and it was used for improving flow of Gandhar crude oil. Characterization of these compounds was done using IR spectroscopy and GPC. From this study it was found that polymeric diesters of oleic acid series was effective in depressing the pour point of the crude oil up to $9^{\circ} \mathrm{C}$ with 500 $\mathrm{ppm}$ doses. More studies were done using polymeric diesters of different doses such as 100, 500, and 1000 ppm at different temperatures to evaluate pour point depressant, study viscosity and share stress and synthesized polymeric additives. In the end it was concluded that better understanding of the resins and asphaltenes along with their role on flow properties of crude oil can help design better PPDs and flow improvers for crude oil transportation. [Hemant et al.(2006)]

\subsection{Poly-Hydrazide}

Crude oil contains n-paraffin wax which is separated from the oil when the temperature drops. The wax crystallizes into an interlocking network of fine sheets. This entraps the petroleum in cage-like structures. The temperature below which the liquid loses its flow characteristics is known as the pour point. Flow properties of crude oil play the most important part in the production, transportation and storage of petroleum. [Camahan et al.(1989), Rafael et al.(2011)] 


\section{International Journal of Engineering Applied Sciences and Technology, 2021 \\ Vol. 6, Issue 1, ISSN No. 2455-2143, Pages 335-352 \\ Published Online May 2021 in IJEAST (http://www.ijeast.com)}

In this study Free-radical polymerization was performed to produce a series of poly-hydrazide $(\mathrm{PH})$ from vegetable oil, hydrazine hydrate and dichloroethane.

Generally, a cold flow improver contains an oil-soluble longchain alkyl group and a polar structure moiety in the molecular structure. These long-chain alkyl group insert into the wax crystal while the polar moiety onto the surface of the wax crystal, thereby inhibiting the crystal lattice formation and decreasing the waxes crystal size. After testing the effectiveness of these PHs on four crude oil it was found that the pour point depression are low effective under lower concentration (50-200ppm), and as the concentration increases up to $500 \mathrm{ppm}$ the PPDs can successfully reduce the pour point by $10.6^{\circ} \mathrm{C}$, further increase of the concentration will not depress the pour point, so the proper concentration is found to be 500 ppm. [Qiang et al. (2016)]

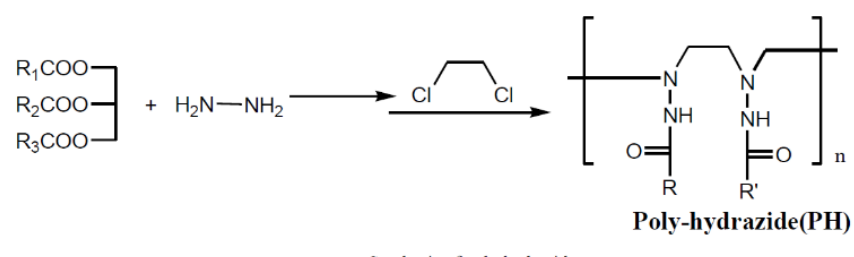

Figure 4: Synthesis of poly-hydrazide [Qiang et al. (2016)]

\subsection{Triethanolamine (TEA)}

Heavy oil is estimated to be at least half of the recoverable oil resources of the world according to Inter Energy Agency (IEA) [Atta et al. (2013)]. Crystallization and deposition of paraffin wax crystals in flow line is one of the main problems during production, transportation and storage which is even more severe in winter [Soni et al. (2005)] The effectiveness of cross sectional area of pipeline decreases when viscosity of crude oil increases due to wax crystal formation. [Anons (2013)] Adding requisite amount of flow improver which is also known as drag reducing agents (DRAs) can improve the pour point and rheological properties of the crude. Pour point depressants are long-chain, ultra-high-molecular-weight that reduces the level of turbulence in fluid streams. [Johnston at el. (2009)]

Caleb et al. (2015) synthesized triethanolamine (TEA) and used it as pour point depressant on Niger-Delta crude oil by changing the feed ratios. Triethanolamine (TEA) has the combined properties of amines and alcohols, and is a part of a class of organic compounds called ethanolamines. It is produced from the reaction of ethylene oxide with aqueous ammonia. It is a weak base, colourless and has a mild ammoniacal odour. The triethanolamine neutralizes fatty acids, adjusts and buffers the $\mathrm{PH}$ and solubilises oil and other ingredients that are not completely soluble in water. Thus this PPD modifies the crystal structure of the paraffin present in the crude oil and helps to reduce the wax, thus improving transportation processes.

\subsection{Ethylene Acrylic Alkyl Ester Copolymer Wax Dispersants}

In this study ethylene acrylic acid copolymer (PEAA) was esterified with 1-docosanol (DcA) in the presence of p-toluene sulfonic acid (PTSA) as a catalyst and xylene as a solvent, which increases the size of the alkyl group. Here characterization was done with FTIR and H NMR methods. During the experiment different doses of the polymeric additive ranging from 1000 to $5000 \mathrm{ppm}$ were used in crude oil. The best result was shown at concentration of $5000 \mathrm{ppm}$ as the pour point depressant and reduce viscosity of samples of Egyptian wax crude oil. [A. M. Atta et al. (2011)]

\subsection{Heter Atoms compounds}

In this study direct reaction of acid with alcohol was done to form esters or acid with amine to form amides which are also termed as Heter Atoms compounds. Ester and amide were produced by esterifing ethylene acrylic acid copolymer (PEAA), was with Hexadecyl alcohol (HAD) and amidation with Hexadecyl amine (HDM). Characterization was done with FTIR and H NMR methods. After diluting the polymeric additives with xylene by $10 \%, 20 \%$ different doses ranging from 500 to $3000 \mathrm{ppm}$ were added to the Norpetco Petroleu Co (NPC) crude oils. Depending on the composition and location of crude oil Pour point temperature reduction from $27^{\circ} \mathrm{C}$ to $3^{\circ} \mathrm{C}$ was seen which was a good measure of pour point reduction. [Enas et al.(2014)]

\subsection{Multifunction Co-Polymer}

The cooling for oils containing paraffin materials results in the formation of a rigid interlocked crystal lattices trapped in to the liquid hydrocarbon materials and prevents flow of oil [Ghosh P and Das T (2014)]. Here, Methacrylic acid (MA) was esterified with $\mathrm{C} 16$ fatty alcohol to synthesis Alkyl methacrylate monomers. $\alpha$ - olefin C16 (1-Hexadecene) was used to polarize Alkyl methacrylate monomers to form copolymer which was then reacted with vinyl acetate monomer to finally give graft copolymer. Characterization was done with FT-IR, H NMR spectroscopy, and gel permeation chromatography (GPC). Graft copolymer with different doses were used which showed very good reduction in the pour point temperature, good rheological behaviors and better friction and wear properties. Particularly oil sample with $5000 \mathrm{ppm}$ showed $-18^{\circ} \mathrm{C}$ reduction in pour point which is very efficient product synthesized in this work.[ Al-Shafey at el.(2018)]

\subsection{Polymeric pour point depressants}

Copolymerization of acrylates of different alkyls with maleic anhydrade was done to synthesis Anhydride copolymers and Poly (n-alkyl acrylates-co-N-hexa decylmaleimide) was prepared by the reaction of copolymer with hexadecylamine. Total Five flow improvers were synthesized and characterized by FTIR, GPC after their purification. Dual function which include, wax dispersants and flow improvement was seen in all the polymers. In the end it was observed that, with the increase of alkyl chain length and with increase of concentration in solution the efficiency of flow improver 
increased for the Nada crude oil (Gujarat, India)[ Srushti at el.(2007)]

\subsection{Emulsified Acrylate Polymer}

Crude oil travels from sea level to surface through pipelines along with gradual decrease in temperature to a point where it reaches the wax appearance temperature (WAT) or the pour point temperature. At this stage asphaltene starts to flocculate and wax starts to crystallize, which lead to wax and asphaltene solids deposition on the inner walls of the pipelines [B. Wei (2015)]. Different methods are available for wax and asphaltene removal. The most common ones are mechanical and chemical removal [A. K. Norland (2012)]. For chemical removal, various kinds of chemicals to remove wax and asphaltene deposits can be used. Here, traditional pour point depressant (PPD) of acrylate polymer was improvised in an emulsion system. The raw materials, PD 90, emulsifier (MWV) and Solvesso 150 were supplied by ACME Chemicals (Malaysia) Sdn. Bhd. Xylene, diethanolamine and ethylene glycol were collected from Merck Sdn. Bhd. PD90 consist of 40 to $60 \mathrm{wt}$. \% of acrylate polymer in xylene. The improved emulsified PPD could flow at as low as $-20^{\circ} \mathrm{C}$.

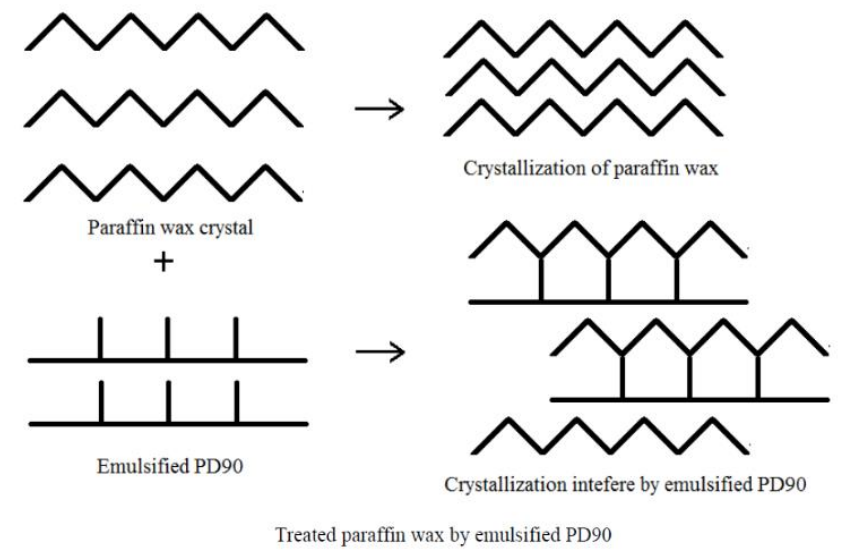

Figure 5: Treated paraffin wax by emulsified PD90 Emulsified product has better pour point performance compared to traditional PPD. Also the viscosity of emulsified PPD at room temperature was much lower than traditional PPD which would also benefit in terms of handling and storage.[ A. Admiral at el.(2016)]

\subsection{Copolymer Solubilized in Organic Solvent with an Aromatic Hydrocarbon}

A wax inhibitor and an asphaltene dispersant is used in this study to prevent the formation of wax and asphaltene deposits. Combination of three substances; a wax inhibitor dissolved in a wax inhibitor solvent and an asphaltene solvent, namely, ethylene-vinyl acetate (EVA) copolymer dissolved in methylcyclohexane $(\mathrm{MCH})$ and toluene (TOL) to inhibit the precipitation and deposition of wax and asphaltene were being used.The Malaysian crude oil was taken from Sabah platform to be used for this experiment. And the reagents used in this experiment were supplied by Merck Sdn. Bhd, Selangor, Malaysia. The Malaysian crude oil has minimal amount of wax but high content of asphaltene. EVA copolymer is used as the wax crystal modifier or wax inhibitor which adheres to the active surfaceof wax molecules, thus, controlling the size of wax crystals from increasing in size or depositing by the pipeline walls. After optimizing the percentage composition of each component for maximizing the viscosity reduction of crude oil it was found that the combination of 50\% EVA + $25 \% \mathrm{MCH}+25 \%$ TOL gave a maximum viscosity reduction of $67 \%$ while the RSM model proved that the combination of $57 \%$ EVA $+20.5 \% \mathrm{MCH}+22.5 \%$ TOL gave a maximum viscosity reduction of up to $61 \%$.[S. M. Anisuzzaman at el. (2017)]

\subsection{Oleic acid based polymeric flow improvers}

With the help of free radical solution polymerization three new comb-shaped copolymers of maleic anhydride and nalkyl oleate were synthesized. These copolymers were reacted with hexadecyl amine to get poly (hexyl oleate-co-hexadecyl maleimide-co-n-alkyl oleate). Characterization was done by Fourier Transform Infrared Spectroscopy (FTIR) and Gel Permeation Chromatography (GPC). Using Fann Viscometer these FIs were further evaluated for their pour point depression property and rheology modifier with and without additive. In the end it was concluded that the synthesized FI acts as effective pour point depressant at higher concentrations. [Mayur et al.(2016)]

\subsection{Comb-type poly (maleic acid alkylamide-co- $\alpha$-olefin)}

$\alpha$-olefin and maleic anhydride were copolymerized to synthesized a series of comb-type poly(maleic acid alkylamide-co- $\alpha$-olefin) (MAC) with different side-chain lengths .This was followed by amidation with alkylamine.

The raw materials of decane (anhydrous, 99\%), hexatriacontane (C36, >98\%,), maleic anhydride (99\%), $\alpha$ octadecene (95\%), $\alpha$-dodecene (95\%), benzoyl peroxide (99\%), o-xylene (98\%), octadecylamine (97\%), and dodecylamine (98\%) were bought from Acros company. Model waxy oil samples were prepared by dissolving C36 nalkanes in decane. At room temperature the asphaltene content was measured by weighting the precipitate formed upon addition of light petroleum ether. Paraffin content was estimated as the precipitate weight upon addition of acetone and cooling to $0{ }^{\circ} \mathrm{C}$. Different methods such as rheology, differential scanning calorimetry (DSC), and optical miceroscopy was carried out to understand the effects on the rheological propertiy (yield stress) and crystallization behaviours of both model waxy oils and crude oils. The efficiency of MAC was increased with longer side alkyl chan length (MAC 18-18 > MAC 12-18 > MAC 2-12) [Jun et al. (2009)].

\subsection{Spirocompound as Clean Viscosity-Reducer}

One of the most technical operation of the oil industry is its transportation and it need to have an efficient and economical solution to deal with the high viscosity crude [E.M. Newberry et al (1984), C.R. Price (1971), D. Chanda (1996)]. In this 


\section{International Journal of Engineering Applied Sciences and Technology, 2021 \\ Vol. 6, Issue 1, ISSN No. 2455-2143, Pages 335-352 \\ Published Online May 2021 in IJEAST (http://www.ijeast.com)}

study a spirocompound, 3,9-diphenyl-2,4,8,10-tetraoxaspiro[5.5] undecane, was synthesized catalyzed by zeolite and modified zeolite.

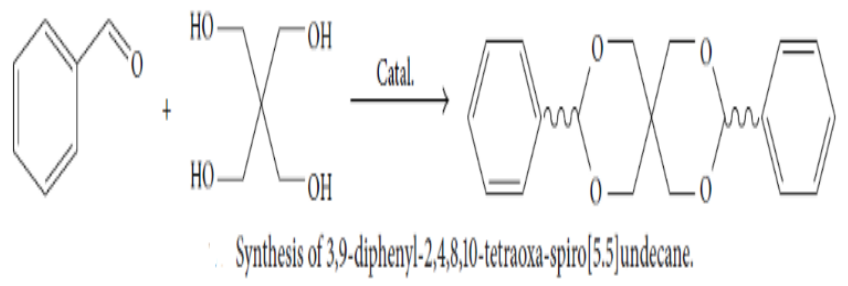

Figure 6: Synthesis of 3,9-diphenyl-2,4,8,10-tetraoxaspiro[5.5] undecane. [Shijun et al. (2-16)]

The Raw materials or chemicals were prepared in our laboratories and others were purchased from Merck, Fluka, and Aldrich Chemical Companies. Characterization of the product was done by comparison of their physical data with those of known samples or by their spectral data with the help of NMR, MS, and TG. After using it as viscosity reducer for crude oil with different doses the results showed a significant viscosity reduction at different temperature. The most economical dosage was $500 \mathrm{ppm}$ which can prevent the agglomeration of wax crystals. [Shijun et al.(2016)]

\subsection{Alkyl Fumarate-Vinvl Acetate Copolymers in Combination with Alkyl Acrylates}

In this study copolymers of n-alkyl fumarate alongside vinyl acetate holding an average chain length of 19.2 as the average carbon number of the alkyl group in combination with polybehenyl acrylate was used to boost the flow properties of Borholla crude oil. The Borholla crude oil is transported in a 12-inch diameter branch pipeline over a distance of $42 \mathrm{~km}$ to the main oil pipeline. The production of crude oil is only about $500 \mathrm{kl}$ per day, while rest of the time the pipeline is shut down for about $10-12 \mathrm{~h}$ per day. So, in order to improve the storage stability of the additive-treated crude another additive, i.e. the polybehenyl acrylate, is also presented. Here Polybehenyl acrylate impart steadiness to the additive-treated Borholla crude oil. The copolymers of alkyl fumarates along side vinyl acetate in amalgamation with polybehenyl acrylate prevents the crude oil from attaining the gel structure on prolonged storage, also boost the restarting ability of the Borholla crude oil. [ Arun et al.(1995)]

\subsection{Low molecular weight polybehenyl acrylate}

Pour point depressant (PPD) can diminish the formation of the wax crystal and forms smaller crystals of a higher volume to surface ratio which changes the crystal shape and the ability of wax crystals to intergrow and interlock largely. Lowering of these two effects together lowers the pour point, viscosity and yield stress considerably which helps the transportation of waxy crude oil [Girma et al. (2018)]

In this experiment, polybehenyl acrylate (PBA) was synthesised, and its efficiency as PPD for Dikom and Kathaluni $(\mathrm{KH})$ crude oils were evaluated. The crude oils were selected on the basis of their similar wax content $(>10 \%)$ and asphaltene content $(>2.5 \%)$. These oil fields are situated in upper Assam, India. Both the crude oils exhibit many similar physical characteristics. Suprior efficiency can be seen for low molecular weight polybehenyl acrylate as PPD for Dikom (DK) and Kathaluni $(\mathrm{KH})$ crude oils. Inclusion of asphaltene soluble solvents such as benzene, xylene, pyridine, nitrobenzene in small quantities (1-5\%) alone or inamalgamation with flow improvers could reduce the pour point, viscosity and yield stress significantly. [D. Chandaa et al.(1998)]

\subsection{Novel Pour Point Depressants}

In this study, terpolymers namely Docosanyl acrylate-co(octadecyl or hexadecyl acrylate)-co-maleic anhydride containing MA (maleic anhydride) as the polar component, DCA (Docosanyl acrylate) as a main long-chain wax like alkyl acrylate and ODA (octadecyl acrylate) or HAD (hexadecyl acrylate) as shorter chain alkyl acrylates were synthesised. The raw materials of Acrylic acid (AA), docosanol (DC), octadecanol(OD), hexadecanol (HD), benzoyl peroxide, hydroquinone,and methyl ethyl ketone (mek) were obtained from Aldrich Chem. Co., Germany. While Xylene was obtained from Adweic Chem. Co., Egypt. Two western deserts waxy crude oils namely Osores and Khalda were used to evaluate the PPDs. Here different compositions of alkyl acrylates $(90: 10,70: 30,50: 50,30$ : 70 , and $10: 90)$ (DCA-ODA)/(MA) or (DCA-HDA)/(MA) were used. The terpolymers was observed to have nonNewtonian pseudoplastic relationships at different concentrations of synthesized terpolymeres with monomer feed ratios of (DCA-ODA $(1: 1)) /(\mathrm{MA})$ or (DCA-HDA $(1$ : 1))/(MA) $1 / 4 \quad 90 / 10$ mole $\%$ with effective concentration of PPD at $250 \mathrm{ppm}$ for Khalda crude oil and $5000 \mathrm{ppm}$ for Osores crude oil. Even at low temperatures the compound showed a good ability to disperse wax crystals and improve the flow behaviors as it was tested for the two western desert crude oil with different wax content. [Rasha et al.(2010)]

\subsection{Methacrylate Based Polymeric Additives}

Non-polar n-paraffins and polar components such as asphalenes and resins are the main components of Crude oil which is a complex mixture of hydrocarbons. [Huang et al. (2011)]. The decrease in temperature causes paraffin precipitates from the crude oil which forms wax crystal networks. [Guo et al.(2006)]. This causes many problems during transportation and storage which is due to the crystallization and deposition of wax crystals in flow line. [ Frohlich et al.( 2005), Atta et al.(2011), Xu et al.( 2011), AlShafey et al.(2011)] To find a solution for this problem Homopolymer of decyl methacrylate and its copolymer with styrene and vinyl acetate were used as flow improver for crude oil in the presence of benzoyl peroxide (BPO) as initiator. The crude oil used for the experiments were collected from Oil India Ltd, Duliajan, Assam. Characterizations of all the polymers were done using FT-IR, NMR and Gel Permeation Chromatography (GPC). The end results of the prepared 


\section{International Journal of Engineering Applied Sciences and Technology, 2021 \\ Vol. 6, Issue 1, ISSN No. 2455-2143, Pages 335-352 \\ Published Online May 2021 in IJEAST (http://www.ijeast.com)}

additives showed very good results as pour point depressant (PPD) in crude oil. [Sultana et al. (2018)]

\subsection{Polymeric structures as cold flow improvers}

In this study, esterification of Acrylic and methacrylic acids was carried out with dodecyl, hexadecyl and NAFOL $20+\left(\mathrm{C}_{\mathrm{av}}\right.$ $=21$ ) alcohols to produce monomers at different molar ratios which was later copolymerized with $\mathrm{C}_{18} \alpha$-olefin. The saturated linear long-chain alcohol blend, NAFOL 20+ was supplied by CONDEA Chemical Co. while other chemicals used were of technical grade. High pour point Egyptian waxy residual fuel oil used for the experiments (IWO) was supplied by Alexandria Petroleum Company. After purification and characterization, the sample was tested as cold flow improvers for a high-pour waxy residual fuel oil (RFO). It was found that only the polymeric structures with long side chains of NAFOL $20+$ have the potential to decrease the pour point and improve the rheological properties of the fuel oil. It was also seen that the storage stability of the treated RFO is good up to 3 days but then diminishes steadily. [I. M. El-Gamal et al.(1997)]

\subsection{Phthalic anhydride-polyethylene glycol ester (PAP)}

In this study, phthalic anhydride and polyethylene glycol (PEG) was used as the reactant and an ester named Phthalicanhydride-polyethylene glycol ester (PAP) was prepared which was then reacted with hexadecanol and synthesized to form PAPE.The raw materials, Phthalic anhydride, p-toluenesulfonic acid, and polyethylene glycol (M $=200,400,600,1000$ ) for the experiment were supplied by Beijing Chemical Reagent Corporation, China; toluene and hexadecanol were provided by Tianjin Guangfu Fine Chemical Research Institute, China. The substances used were analytical grade reagents and employed without further purification. The T1804 was derived from Beijing Xingyou Chemical Corporation, China. Three diesel oil samples (A, B, C) were obtained from Haike Petrochemical Corporation, Zhongyuan Petrochemical Corporation, and Yanhua Petrochemical Corporation, respectively. Characterization was carried out with H NMR spectroscopy. After studying the characteristics of PEG, it was used as dispersant for diesel effect of PAP and PAPE, the cold filter plugging point (CFPP) can be seen to reduce by $-15^{\circ} \mathrm{C}$ and $-14{ }^{\circ} \mathrm{C}$, respectively, also it has a good synergistic effect when combined with PPD, which contained vinyl acetate monomer. [Wanhang et al. (2014)]

\subsection{PE-b-PEP diblock copolymers}

This study demonstrates that diblock polymers consisting of a crystallizable polyethylene (PE) block and an amorphous poly ethylenepropylene (PEP) block self-assemble in oil to form expansive plate-like aggregates, consisting of a PE core within a PEP brush layer, which can effectively reduce the yield stress of paraffin wax gels, which shows that it can be successfully used as flow improver agents for waxy crude oils and fuels. [Henry et al. (2002)]

\subsection{Modulating Long-Chain Paraffin Crystallization with Comb Polymers, (by X-ray Diffraction)}

In this study the crystallization of long-chain n-paraffins (from solutions of decane) was studied by X-ray diffraction in order to understand the flow improvement of waxy crude oils of comb-type polymer additives. Here, poly(ethylenebutene) (PEB) and poly(maleic anhydride amide-co-R-olefin) (MAC) polymers on the crystallization of $\mathrm{C} 28, \mathrm{C} 32$, and $\mathrm{C} 36 \mathrm{n}$ paraffins and their mixtures were examined to see their effects. When no PPD is added the paraffin platelet crystals give well-resolved low-angle spectra. And on addition of PEB or MAC, the low-angle scatterings from the layered structures were reduced and even disappeared. This shows that the polymers anchor into crystals by cocrystallization with the paraffins by their polyethylene blocks (for PEB) or alkyl grafts (for MAC)and the non crystallizable parts of the polymer chain form a polymer layer to provide a steric barrier against platelet stacking. Thus the assembly of PEB and MAC with paraffins during crystallization resulted in improving the flow of waxy oils on cooling. [Li Li et al. (2010)]

\subsection{Polymeric Additives Based on Vinyl Acetate Copolymers}

Here, maleic anhydride ester-co-vinyl acetate copolymers with varied monomers feed ratios and different alkyl ester lengths, namely, dodecyl, stearyl, and behenyl alkyl chains were synthesized and characterized by FTIR, HNMR and GPC. The molecular weight and composition of the flow characteristics of wax crude oil were studied at low temperature. Hydrophobically modified stearyl maleate-vinyl acetate (VASM) copolymers was produced which was an efficient PPD for the Egyptian waxy crude oil. Here, 100-10000 ppm was the effective concentration for the PPD to inhibit the wax deposition, to decrease the pour point temperature, and to improve the rheological characteristics of crude oils. This study showed that stearyl maleate-vinyl acetate copolymer with $1: 2$ feed ratio had the best efficiency as pour point depressant even at low concentration while octadecyl maleatevinyl acetate copolymers with $2: 1$ feed ratio was effective as flow improver.[AymanM et al. (2015)]

\subsection{Polymethyl Methacrylate- Graphene Oxide Nano- Hybrid Polymers}

The nano-hybrid polymers of polymethyl methacrylategraphene oxide (PMMA-GO) were successfully prepared, well characterized by FT-IR and Raman spectroscopy, XRD, RHTEM, SEM and GPC chromatography was then applied for improving the pour point and flowability of wax crude oil. The working function of the nano-hybrid polymers is to absorb the PMMA and co-recrystaized with paraffin chains which alters the size and crystal shape of wax crystal, along with the GO nano sheets with oxygen. This act as heterogeneous nucleation sites and charged wax crystals causing electrostatic repulsion between wax crystals to hinder the formation of wax network, ultimately increasing the wax 
solubility and improving flow capacity of wax crude oil.[Ahmad et al. (2016)]

\subsection{Hydrophobically Modified Polyampholyte}

Here, hydrophobically modified polyampholyte $\operatorname{poly}(N, N$ diallyl- $N$-octadecylamine-alt-(maleic acid)) was used as PPD which was very effective for crude oil of the Akshabulak oil field. Here,100-500 ppm dosage of the PPD had shown effective results in reducing the amount of paraffin crystals to decrease the pour point temperature, and improve the rheological characteristics of crude oil. The presence of long hydrophobic chains and strongly interacting zwitterionic moieties in the polymer is the reason for effective hydrophobically modified polyampholyte. [Francois et al. (2005)]

\subsection{Four sets of copolymeric additives}

Here, copolymerization of dialkyl fumarates and dialkyl maleates with vinyl acetate (VAc) and vinylpyrolidone (VP) monomers was carried out to synthesize four sets copolymeric additives. Two groups of diesters (Dialkyl esters) were synthesized by esterification of maleic and fumaric acids with a series of n-alkanol having an increasing number of carbon atoms. Here characterization was done using spectroscopic analysis. Different parameters of molecular weight of the produced copolymers were determined and studied along with the efficiency as flow improver and its viscosity index. The dialkyl fumarate copolymers had higher molecular weight then the corresponding dialkyl maleate copolymers. The efficiency of both the groups of copolymers increases with increasing the chain length of the alkyl group. After studies, it was concluded that the dialkyl ester/VP copolymers are more efficient as viscosity index improver while copolymers based on didodecyl fumarate/VAc are more effective as pour point depressants [Abdel et al. (2001)].

\subsection{Synthesized polymeric pour point depressant (PPD) from olive oil}

Novel pour point depressant synthesized from vegetable olive oil (Olea Europaea) was used as pour point depressant to improve the reological properties. Here, crude oil samples having wax content $16.5 \%$ was taken from the western oil fields, ONGC, India. During experimentation, the original ambient temperature of $43^{\circ} \mathrm{C}$ was reduced by $8^{\circ} \mathrm{C}$ after addition of $1000 \mathrm{ppm}$ PPD. The viscosity was reduced by $89.20 \%$ after mixing $1000 \mathrm{ppm}$ PPD at $45^{\circ} \mathrm{C}$. These changes helped in reducting heat treatment cost of crude oil during transportation through pipelines in cold weather conditions [Anas et al. (2019)]

2.39 Comb-type co-polymers of polymaleic anhydride-co$\alpha$-olefin-co-styrene (MASC)
With the help of free radical co-polymerization, compounds of Comb-type co-polymers of MASCs with different ratios of styrene/ $\alpha$-octadecene were successfully synthesized to examine the effect of aromatics of the crystallization behavior of waxy gels with low content of asphaltenes. Characterization was done with the help of nuclear magnetic resonance to obtain the chemical structure of the co-polymers. To conform the as-synthesized MASC copolymers tests such as solubility and melting point test were performed. When MASC is added with a higher ratio of styrene/ $\alpha$-octadecene it increases the yield stresses of model oils while it decreases the yield stress of model oils with asphaltenes. The change of morphology of wax crystals from model oils with and without asphaltenes observed by optical microscopy is consistent with the rheological results.

For only wax sample, better results are shown by the MASC with less aromatic units in crystal size reduction. While for asphaltenes sample, the MASC with more aromatic units results in a less amount of crystals even though they were similar in size. [Jun et al. (2010)]

\subsection{Maleic anhydride copolymers (MAC) and polyethylene butene polymers}

After the testing of model waxy oil with asphaltenes to understand the significance of polymers where the crystalline and /or polar content were present it was found the efficiency of the polymers such as reduction of precipitation temperature, gelation temperature, or yield stress lies with the crystalline nature of the polymer. A set of maleic anhydride copolymers with alkyl appendages of different lengths were examined to know the effect of crystalline content. Different aromatic and/or polar functionalities were used into the maleic anhydrade copolymers (MAC) and polyethylene butane polymers to probe potential interactions with the asphaltenes. The results were measured by testing their effect upon precipitation temperature, gelation temperature, and yield stress. Here, the presence of polar functionalities designed to target interactions with the asphaltenes was not beneficial. MAC polymer showed the best results for wax tested (C20C48). While C22 alkyl tails (2000-fold reduction) showed the greatest reduction in yield stress. $\mathrm{C} 18$ alkyl tail showed much smaller reduction (20 to 35 -fold). Whereas, C12 alkyl tail were not effective. [Jack et al. (2009)]

\subsection{Vinyl acetate-behenyl fumarate copolymer}

By using solution polymerization method on varity of solvents, a number of alkyl fumarate - vinyl acetate copolymers having a wide range of molecular weights was prepared. The efficacy of these copolymers as flow improvers (FI)/pour point depressants (PPD) was tested and found that Vinyl acetate -behenyl fumarate copolymer can be used as flow improver for high waxy crudes containing $(<0.5 \mathrm{wt} \%)$ asphaltenes. Molecular weight is an important factor for the efficieny of copolymer and the inclusion of surface active agents is critical for the improvement of the reological behavior of gelled crude oil. The best performance as flow improver for gelled BH crude oil was shown by 300ppm of 
higher molecular weight copolymer PPDI containing $50 \mathrm{ppm}$ of surface-active agent, the esterified product of styrene maleic anhydride copolymer with cetyl amine [A. Borthakur et al. (1996)]

\subsection{Madhuca longifolia}

Naturally extracted surfactant from Madhuca longifolia which is available abundantly in northern India was used in as flow improver for heavy crude oil. Pressure drops reduced greatly with increasing percentage of water dispersed in oil at higher temperature $\left(40^{\circ} \mathrm{C}\right)$. It was seen that heating the crude oil from $25^{\circ} \mathrm{C}$ to $40^{\circ} \mathrm{C}$ reduced the pressure drop from 10.6 psi to 4.3 psi at a flow rate of $60 \mathrm{~L} / \mathrm{min}$ whereas addition of $2000 \mathrm{ppm}$ surfactant at $25^{\circ} \mathrm{C}$ reduced the pressure drop to 2.6 psi at same flow rate. At same temperature, when 2000 ppm surfactant was added to the crude oil, the head loss decreased from 6.77 $\mathrm{L} / \mathrm{min}$ to $4.88 \mathrm{~L} / \mathrm{min}$. Also the viscosity reduction at $25^{\circ} \mathrm{C}$ after addition of 2000 ppm surfactant was even greater than heating the crude to $40^{\circ} \mathrm{C}$. Significant effect on drag reduction as been observed with the use on Madhuca longifolia. The drag force and pressure drop can be reduced enormously for long distance pipeline transportation of crude along with reduce energy loss and head loss. Also, as the extracted surfactant is organic and used in small dosage it does not hamper the downstream refining processes [ Ravindra et al. (2017)]

\subsection{Esters of styrene-maleic anhydride copolymers}

Here, styrene was reacted with maleic anhydride. The product obtained was esterified with fatty alcohols to synthesis esters of styrene -maleic anhydride copolymers. It was then purified and used as pour point depressants for residual fuel oils. The reasons for choosing styrene-maleic anhydride copolymers as the PPD was the simplicity of its preparation and the possibility of obtaining the raw materials locally, and also the expected good response with local residual fuel oils. On comparing the PPD with the available commercial additives the prepared esters of styrene-maleic anhydride copolymers which had molecular weights in the range of 46000 to 118000 showed satisfactory results as pour point depressants with storage stability upto 4 weeks for residual fuel oils [Hamdi et al. (1985)]

\subsection{Polymer of Maleic anhydride with Pentaerythritol stearic diacetate (PSM)}

In this study, polymer of maleic anhydride was synthesis with Pentaerythritol stearic diacetate (PSM) and used as pour point depressant for diesel with different sources. These sources include crude oils collected from Daqing, Liaohe, Shengli and Fuyu regions. The procedure consisted of esterification, polymerization and test of polymer of maleic anhydride with pentaerythritol stearic diacetate for pour point depression. The effects of the PSM were compared with several PPDs made in China and USA. The study showed satisfactory and better results while comparing it to PPDs made in China and USA [Liao et al. (2007)]

The TI805, TI805 are from China, while the ECA8401 and 5920 are made in USA. From the experimental results, the added amount is $0.100 \%$, polymer of maleic anhydride with pentaerythritol stearic diacetate has the similar effects as the PPDs tested.

\subsection{Three phthalimide and three succinimide copolymers}

In this study, three phthalimide and three succinimide copolymers of vinyl acetate, styrene and methyl methacrylate were synthesized, characterized and used as flow improvers for waxy cude oil. The compounds were named as: (VA)Ph; (St)Ph;(MMA)Ph; (VA)S; (St)S and (MMA)S. The raw materials; urea, acrylic acid, vinyl acetate, methanol, toluene, p-toluene sulfonic acid, ethanol and hydroquinone were collected from Sigma Aldrich chemicals company; phthalic anhydride

and succinimide from Loba chemicals company; methyl methacrylate and styrene from Acros chemicals company; formaldehyde solution (37\%) from El-Nasr pharmaceutical chemicals company; xylene and N,N dimethyl formamide from Morgan chemicals company. And the initiator benzoyl peroxide was recrystallized from methanol. Characterization of the compounds was done using FTIR and HNMR. After analysis it was found that when using $(\mathrm{St}) \mathrm{Ph}$ copolymer at 15 ${ }^{0} \mathrm{C}$ and $500 \mathrm{ppm}$ the Bingham yield value $\left(\tau_{\beta}\right)$ decreased from 0.286 to $0.021 \mathrm{~Pa}$, along with the decrease of dynamic viscosity from $358 \mathrm{mPa}$ s to $66 \mathrm{mPa}$ s which has a dramatic economical effect in the process of waxy crude oil transportation. Thus, the results shows that all additives satisfy most of the requirements to act as pour point depressants and flow Improvers. [A.M. Al-Sabagh et al. (2013)]

Table 3: PPD results [Liao et al.(2007)]

\begin{tabular}{|c|c|c|c|c|c|}
\hline \multirow[t]{2}{*}{ Source } & \multirow{2}{*}{$\begin{array}{l}\text { PPD and its } \\
\text { amount }(\%)\end{array}$} & \multicolumn{2}{|l|}{$\mathrm{SP} / \mathrm{C}$} & \multicolumn{2}{|l|}{ CFPP/C } \\
\hline & & $\begin{array}{l}\text { Without } \\
\text { PPD }\end{array}$ & $\begin{array}{l}\text { With } \\
\text { PPD }\end{array}$ & $\begin{array}{l}\text { Without } \\
\text { PPD }\end{array}$ & $\begin{array}{l}\text { With } \\
\text { PPD }\end{array}$ \\
\hline \multirow{8}{*}{$\begin{array}{l}\text { O\# } \\
\text { diesel, } \\
\text { Oil } \\
\text { Refinery } \\
\text { No 2, }\end{array}$} & PSM at & -5 & $<-13$ & -3 & -4 \\
\hline & 0.100 & -5 & $<-12$ & -3 & -3 \\
\hline & & -5 & $<-13$ & -3 & -3 \\
\hline & TI804 at & -5 & $<-13$ & -3 & -4 \\
\hline & 0.100 & -5 & $<-12$ & -3 & -3 \\
\hline & $\begin{array}{l}\text { TI805 at } \\
0.100\end{array}$ & & & & \\
\hline & $\begin{array}{l}\text { ECA8401 } \\
\text { at } 0.100\end{array}$ & & & & \\
\hline & $\begin{array}{l}5920 \text { at } \\
0.100\end{array}$ & & & & \\
\hline$-10 \#$ & PSM at & -12 & -48 & - & - \\
\hline diesel, & 0.500 & -12 & -23 & - & - \\
\hline
\end{tabular}




\begin{tabular}{|c|c|c|c|c|c|}
\hline $\begin{array}{l}\text { Oil } \\
\text { Refinery } \\
\text { No 2, }\end{array}$ & $\begin{array}{l}\text { TI804 at } \\
0.500 \\
\text { TI805 at } \\
0.500 \\
\text { ECA8401 } \\
\text { at } 0.500 \\
5920 \text { at } \\
0.500\end{array}$ & $\begin{array}{l}-12 \\
-12 \\
-12\end{array}$ & $\begin{array}{l}-40 \\
-29 \\
-30\end{array}$ & $\begin{array}{l}- \\
- \\
-\end{array}$ & $\begin{array}{l}- \\
- \\
-\end{array}$ \\
\hline $\begin{array}{l}-350 \# \\
\text { diesel, } \\
\text { Oil } \\
\text { Refinery } \\
\text { No 2, }\end{array}$ & $\begin{array}{l}\text { PSM at } \\
0.100 \\
\\
\text { TI804 at } \\
0.100 \\
\text { TI805 at } \\
0.100 \\
5920 \text { at } \\
0.500\end{array}$ & $\begin{array}{l}<-45 \\
<-45 \\
<-45 \\
<-45\end{array}$ & $\begin{array}{l}<-50 \\
<-50 \\
<-50 \\
<-50\end{array}$ & $\begin{array}{l}-29 \\
-29 \\
-29 \\
-29\end{array}$ & $\begin{array}{l}-33 \\
-27 \\
-32 \\
-31\end{array}$ \\
\hline
\end{tabular}

\subsection{Poly(n-Alkyl Itaconate-Co-Vinyl Acetate)}

In this study, series of (n-alkyl itaconate-co-vinyl acetate) comb-like structure copolymer additives with different alkyl groups from $\mathrm{C} 16$ to $\mathrm{C} 22$ and different monomers molar ratios were synthesized. The raw materials: itaconic acid, hexadecyl alcohol, octadecyl alcohol, two linear saturated long chain alcohol blends NAFOL 20pA and NAFOL 1822 B were purchased from Condeu Chemical Company. While vinyl acetate was purchased from Aldrich and distilled under reduced pressure before use. Toulene, p-toluene sulphonic acid, dibenzoyl peroxide, and other common chemicals used were of laboratory grade reagents. Lube oil sample was brought from Suez Oil Processing Company (SOPC), Egypt. Characterization was done using FTIR, HNMR and GPR, and used as pour point depressant. It was seen that the efficiency of the copolymers as PPDs increased with the increase in concentration of the additive. The efficiency was also increased by decreasing the size of the pendant alkyl group while increasing the mole fraction of vinyl acetate in the copolymer. [A.M. Al-Sabagh et al. (2012)]

\subsection{Poly(styrene-co-octadecyl maleimide)}

The combined reaction of poly(styrene-co-maleic anhydride) with octadecyl amine lead to the synthesis of poly(styrene-cooctadecyl maleimide) with different degrees of imidization which was used as flow improver for waxy oil. The Poly(styrene-co-maleic anhydride) samples of SMA1000P, SMA2000P, and SMAEF40 were collected from Sartomor Company. While other chemicals i.e, n-Octadecyl amine (ODA), n-decane, and n-tetracosane were purchased from Acro; Chloroform ( $\mathrm{CHCl} 3)$, anhydrous methanol, tetrahydrofuran (THF), and ethyl benzene (EB) were provided by Sinopharm Chemical Reagent, and all materials were used without further purification. After experimentation it was seen that using these flow improvers the crystallization temperature and yield stress could be reduced by $3.6^{\circ} \mathrm{C}$ and 70 times, respectively. Here the degree of imidization affects the performance of the Flow improvers. The flow improver becomes more compatible with nonpolar paraffins when more maleimade groups are created from maleamic acid groups by increasing the degree of imidization [Kun et al. (2012)].

2.48 Biosurfactant from Pseudomonas putida and Halomonas xianhensis (Bacteria)

Biosurfactant are a type of PPD which can be used in petroleum [Okoliegbe and Agrarry (2012)]. Mulligan et al (2001) describes the biosurfactants as the surface-active biomolecules produced by microorganisms with a wide range of applications. Here, the cellular growth of biosurfactant production is affected by growth conditions such as $\mathrm{pH}$, temperature, agitation, and oxygen availability [Lang and Philp (1998)]

In this study, biosurfactant were produced using two bacteria namely, Pseudomonas putida (B1) and Halomonas xianhensis (B2) which were grown on Bushnell Haas mineral salt medium. The determination of the qualitative indication of biosurfactant production in the medium culture was done by reduction in surface tension and an increase in the emulsification power. The activity of the biosurfactants was observed under the influence of salinity and $\mathrm{pH}$, and found that good resistance of $\mathrm{NaCl}$ concentration upto $20 \%$ is shown by two bacterial strains. Pseudomonas putida could be seen with surface activity of biosurfactant with maximum value of pH 7 while Halomonas xianhensis was not affected by the change of $\mathrm{pH}$ value (3-12). This was good for industrial scale production. After testing the two biosurfactants B1 and B2 it was seen that the order in which effectiveness of PPD increased was B2> B1> combined B1 and B2. Thus these studies give the qualitative indication of suitability of additives for improving the flow properties of crude oil [H. S. El-Sheshtawy and T.T Khidr (2016)]

\subsection{Long chain acrylic esters polymers with polar monomers}

Depending on the field of production crude oil contains wide range of components ranging from hydrocarbons, paraffin etc. A major constituent being paraffin wax which is relatively insoluble and precipitate when cooled down below certain temperature. [Jorda (1966), Agrawal et al.(1991), Wang et al.(1999)]. In this study, 22 polymer additives of defined and controlled structural characteristics were used in improving the flow properties of crude oil and studied. Synthesis of these additives was performed by the solution polymerization of alkyl acrylates of various alkyl chain lengths with styrene, acrylic acid and 1-vinyl-2-pyrrolidone as copolymers or terpolymers. Polymerization was performed by tertbutylperoxy-2-ethylhexanoate as initiator in xylene at $92{ }^{\circ} \mathrm{C}$, up to high conversion. Studies showed that the efficiency of the additive depends on its composition, polarity, as well as on crude oil properties, its n-paraffin content and distribution. 


\section{International Journal of Engineering Applied Sciences and Technology, 2021 \\ Vol. 6, Issue 1, ISSN No. 2455-2143, Pages 335-352 \\ Published Online May 2021 in IJEAST (http://www.ijeast.com)}

The additives in this process could be used directly without purification which is one of the main advantages for this method. [Ana et al.(2008)]

\subsection{Natural seed oil to act as flow improver}

Natural seed oil obtained from agricultural sources such as rubber seed (RSO), Jatropha seed (JSO) and castor seed (CSO) were used as flow improver and pour point depressant for Nigerian waxy crude oil.

The reagents(xylene, triethanolamine, hexane) used were analytical grade products of $\mathrm{BDH}$ Chemical Ltd, Poole England. Four crude oil samples obtained through the Department of Petroleum Resources (DPR) from major oil companies in the Niger Delta region of Nigeria were used in the study. It was seen that Jatropha and castor seed oils could depress the pour point upto $17^{\circ} \mathrm{C}$ and also reduce the viscosity of the waxy crude oil appreciably within $0.1-0.3 \%(\mathrm{v} / \mathrm{v})$ dosing concentration. Also, JSO exhibit $73.5 \%$ paraffin inhibition efficieny while CSO exibit as high as $77.7 \%$ paraffin inhibition efficiency at low concentration of doping. [Olusegun et al. (2016)]

\subsection{BEM series of PPDs}

BEM series of PPD are copolymer of an alkene, an unsaturated ester and a polar monomer.

The structural formula can be written as:-

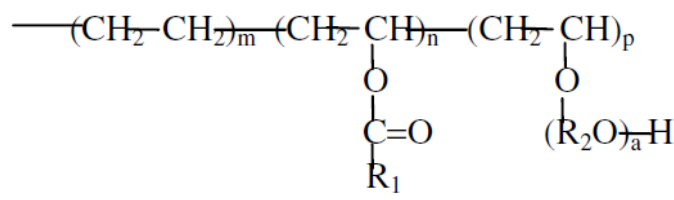

Figure 6: BEM series of PPD [Fusheng et al. (2001)]

These PPDs were used in China for crude oil transportation in Luning, Zhongluo, Pulin, Weijing, Donghuang and Donglin etc through long distance pipelines, (at dosage of $50 \mathrm{mg} / \mathrm{kg}$ ). Using the PPDs it was observed that the pour points of the above mentioned crude oils were reduced by $19{ }^{\circ} \mathrm{C}, 19.5{ }^{\circ} \mathrm{C}$, $18{ }^{\circ} \mathrm{C}, 13.5{ }^{\circ} \mathrm{C}, 13{ }^{\circ} \mathrm{C}$ and $20{ }^{\circ} \mathrm{C}$ respectively while viscosities of above-mentioned crude oils were reduced by $84.6 \%$, $94.9 \%, 97.5 \%, 93.0 \%, 15.7 \%$ and $23.0 \%$ respectively. This resulted in a tremendous economic benefit as more than 40 tousand tons fuel was saved per year, and more than 28 million yuans RMB was saved per year after deducting cost of PPD,also safety and flexibility of pipelines operation were enchanced [Fusheng et al. (2001)]

\subsection{Terpolymer}

In this paper, semi-continuous emulsion polymerization was done to synthesize a series of effective terpolymer additives which was used as PPDs to improve the flow of heavy Mexican Crude oil(MCO). It was observed that when a small quantity of polar co-monomer (BuA or $\mathrm{VA}$ ) is introduced in the terpolymer backbone, it has an effect on the reduction of apparent viscosity in this type of heavy crude oil. While, the addition of a great quantity of $\mathrm{S}$ as a component of the terpolymer shows a conclusive effect on the flow improvement of petroleum. It was witnessed that choosing an adequate molecular weight of the polymer additive is important. A spectroscopic and size-exclusion chromatography (SEC) method was carried out to characterize the polymeric additives. When terpolymers added to the MCO it was seen that the rheological properties requirements of flow improvers are well satisfied. [Laura et al.(2011)]

\subsection{Polyacrylate}

In this study, Monte Carlo simulation was employed to study the interaction of crude oil waxes with Polyacrylate PPDs of different structures, using n-hexadecane as representative component of wax crystal. The compatibility of PPDs with crude oil waxes depends on the side chain carbon numbers of acrylate monomers which should be close to the averaged carbon number of crude oil waxes. Also the waxes repellent fragments of PPDs should consist of building blocks with strong polarity. Under these conditions the PPD would effectively inhibit wax crystal precipitation and improve crude oil low temperature fluidity [Z. Chen et al. (2014)]

\subsection{Aqueous surfactant}

Yousef Al-Roomi et al.(2004) synthesized an aqueous surfactant solutions which could convert viscous heavy crude oil into low viscosity oil in water emulsion. This new surfactant has high potential as it could reduce the viscosity of heavy crude oil emulsions even though it comprises a very low concentration in emulsion when compared with the commercial non-ionic surfactants. Also the newly designed surfactant molecule have the advantages of low cost and lower mixing energy when compared with those based on the commercial surfactant. The surfactant showed a good correlation coefficient which was higher than $93 \%$.

\subsection{Graphene-Based Novel Nanocomposite PPDs}

Here, novel polymer nanocomposites poly(2-ethylhexyl acrylate)-graphene oxide [P(2-EHA)-GO] were synthesised using $0.5-2$ wt \% GO concentrations by in situ free-radical polymerization. In order to conform the formation of nanocomposites, characterization was done using different analytical techniques. A notable $18{ }^{\circ} \mathrm{C}$ depression in the pour point and upto $99 \%$ reduction in its apparent viscosity (down to $0.01 \mathrm{~Pa} \mathrm{~s}$ ) was observed by using an optimized amount of GO (1 wt $\%$ ) nanocomposite. The gelation point was also reduced upto $17.8^{\circ} \mathrm{C}$ which resulted in improving the flowability of crude oil [Rohit et al. (2019)]

\section{CONCLUSION}

Various methods are developed to improve the flow ability of crude oil in low temperatures. In the recent developments of flow assurance techniques, PPD has become a new research subject for the crude oil production. In this review we try to 
discuss some these PPDs which are developed by various personals and used for flow assurance to prevent the formation of waxy crystals and solve the problems of crude oil such as plug formation, wax formation, asphaltene formation etc and improve the flow. It is hoped that at some point in the future, the application of pour point depressant can help eliminate or reduce the impact of many of flow assurance issues.

\section{REFERENCES}

1. A. Admiral, M.K. Abdullah, A. Ariffin (2016). Evaluation of Emulsified Acrylate Polymer and Its Pour Point Depressant Performance (C) 2016 The Authors. Published by Elsevier B.V. This is an open access article under the CC BY-NC-ND license

2. A. Borthakur, D. Chanda, S. R. Dutta Choudhury, K. V. Rao, and B. Subrahmanyamn (1996), Alkyl Fumarate-Vinyl Acetate Copolymer as Flow Improver for High Waxy Indian Crude Oils (C) 1996 American Chemical Society

3. A. E. Erceg Kuzmi'c, M. Rado`sevi'c, G. Bogdani'c, V. Sri'ca, and R. Vukovi'c(2008), Studies on the influence of long chain acrylic esters polymers with polar monomers as crude oil flow improver additives, Fuel, vol. 87, no. 13-14, pp. 2943-2950, 2008.

4. A. K. Norland(2012) Organic flow assurance, pour point depressant development through experimental design, University of Stavanger, Norway, 2012.

5. A. M. Al-Sabagh , T. M. Khalil, M. W. Sabaa, T. T. Khidr \& G. R. Saad (2012) , Poly(n-Alkyl Itaconate-Co-Vinyl Acetate) as Pour Point Depressants for Lube Oil in Relation to Rheological Flow Properties Journal of Dispersion Science and Technology, 33:1649-1660, 2012 (C) Copyright Taylor \& Francis Group, LLC

6. A. M. Atta, H. I. Al-Shafy, and E. A. Ismail(2011). Influence of Ethylene Acrylic Alkyl Ester Copolymer Wax Dispersants on the Rhological Behavior of Egyptian Crude Oil Journal of Dispersion Science and Technology, 32:1296-1305, 2011 Copyright Taylor \& Francis Group, LLC ISSN: 0193-2691 print=1532-2351 online

7. A.M. Al-Sabagh, S.H. Al- H. El-Hamouly , T.T. Khidr , R.A. El-Ghazawy ,Sh.A. Higazy (2013), Synthesis of phthalimide and succinimide copolymers and their evaluation as flow improvers for an Egyptian waxy crude oil Egyptian Journal of Petroleum (2013) 22, 381-393

8. A.M. Al-Sabagh , M.R. Noor El-Din , R.E. Morsi , M.Z. Elsabee (2009)Styrene-maleic anhydride copolymer esters as flow improvers of waxy crude oil.0920-4105/\$ - see front matter (C) 2009 Elsevier B.V. All rights reserved.

9. Abdel-Azim A. Abdel-Azim and Rash M. AbdelAziem (2001), Polymeric Additives for improving the flow properties and Viscosity Index of
Lubricating Oils, J. Polym. Res., Vol. 9, No. 2, 111 118, June 2001

10. Agrawal MK, Surianarayanan M, Dilawar KVS, Joshi CG.(1991) Effect of flow improver additives on wax deposition. Erdöl Kohle Erdgas, Petrochem 1991;44:375-6.

11. Ahmad Mohamad Alsabagh, Mohamed A. Betiha, Doaa I Osman, Ahmed I. Hashim, Mohamed M. ElSukkary, and Tahany Mahmoud (2016) Preparation and Evaluation of Polymethyl MethacrylateGraphene Oxide Nano-Hybrid Polymers as Pour Point Depressants and Flow Improvers for Waxy Crude Oil Energy Fuels, Just Accepted Manuscript acs.energyfuels.6b01105 - Publication Date (Web): 03 Aug 2016

12. Akanksha Prasad, Prof Kavita Kulkarni, Prof A.D.Kulkarni, Prof. P.L.Chaudhari, Prof. S.C.Bandpatte(2019). Pour Point Depressant of Crude Oil. International Journal of Chemical Engineering Research. ISSN 0975-6442 Volume 11, Number 2 (2019), pp. 81-90 (C) Research India Publications.

13. Al-Shafey HI and Arafa EI(2018) Synthesis and Evaluation of Multifunction Co-Polymer as Lubricating Oils Additives Pet Petro Chem Eng J 2018, 2(4): 000159

14. Al-Shafey, A. H. I., Hashem, A. I., Abdel Hameed, R. S., and Dawood, E. A. (2011). Studies on the Influence of long chain acrylic esters co-polymers grafted with vinyl acetate as flow improver additives of crude oils. Adv. Appl. Sci. Res. 2 (5): 476-489.

15. Ana Erceg Kuzmic, Marko Radoševic , Grozdana Bogdanic , Vlasta Sric, Radivoje Vukovic(2008), Studies on the influence of long chain acrylic esters polymers with polar monomers as crude oil flow improver additives 2008 Elsevier Ltd. All rights reserved.

16. Anas Azeem, Rahul Kumar, Biswadeep Pal, and Tarun Kumar Naiya Use of novel pour point depressant synthesized from vegetable oil for waxy crude oil Department of Petroleum Engineering, Indian Institute of Technology (ISM), Dhanbad 826004, India $\odot 2019$ Taylor \& Francis Group, LLC

17. Anonymous, (2013). Oilfield Drilling and Exploration Chemicals: Pour Point Depressants. www.constol.co.in/pro_oil_ppd.asp. (June 23, 2013).

18. Arun Borthakur, Narayan C. Laskar, Ranjit K. Mazumdar, Kosuru V. Rao \& Bulusu Subrahmanyam(1995). Synthesis and Evaluation of Alkyl Fumarate-Vinvl Acetate Copolymers in Combination with Alkyl Acrylates as Flow Improvers for Borholla Crude Oil J. Chem. Tech. Biotechnol. 0268-2575/95/\$09.00 01995 SCI. Printed in Great Britain 
19. Atta, A. M., Al-Shafey, H. I., and Ismail, E. A. (2011). Influence of ethylene acrylic alkyl ester copolymer wax dispersants on the rheological behaviour of Egyptian crude oil. J. Dispersion Sci. Technol. 32:1296-1305.

20. Atta, A.M., El-Ghazawy, R.A., Morsy, F.A., Ali, M.S.A. and Elmorsy, A. (2013). Synthesis and Characterization of Polymeric additives and their effect on flow properties of waxy Egyptians Crude Oil. Global Journal of Science Frontier Research Chemistry. 13(10), $21-27$.

21. AymanM. Atta, Rasha A. El-Ghazawy, Fatma A.Morsy, AliM. S. Hebishy,3 and Abdullah Elmorsy(2015), Adsorption of Polymeric Additives Based on Vinyl Acetate Copolymers as Wax Dispersant and Its Relevance to Polymer Crystallization Mechanisms. Academic Editor: Chao Jin Copyright (C) 2015

22. AymanM. Atta, Rasha A. El-Ghazawy, Fatma A.Morsy, AliMohamed Salah Ali, and Abdullah Elmorsy(2015). Adsorption of Polymeric Additives Based on Vinyl Acetate Copolymers as Wax Dispersant and Its Relevance to Polymer Crystallization Mechanisms Hindawi Publishing Corporation Journal of Chemistry Article ID 683109 Copyright (C) 2015

23. B. Wei,(2015) Recent advances on mitigating wax problem using polymeric wax crystal modifier, J. Pet. Explor. Prod. Technol., vol. 5, no. 4, pp. 391401, 2015.

24. Borthakur A., Laskar N.C., Mazumdar R.K., Rao K.V., Subrahmanyam B.(1995), Synthesis and evaluation of alkyl fumarate-vinyl acetate copolymers in combination with alkyl acrylates as flow improvers for Borholla crude oil, J. Chem. Tech. Biotechnol., 62, 75-80, 1995.

25. C. R. Price (1971), Flow improvers for waxy crudes, Journal of the Institute of Petroleum, vol. 57, pp. 106-109, 1971.

26. C. R. Price,(1971) Flow improvers for waxy crudes, Journal of theInstitute of Petroleum, vol. 57, pp. 106-109, 1971.

27. Caleb Abiodun Popoola, Jerome Adekunle Ayo, Olajide Emmanuel Adedeji and Ogungbemi Akinleye(2015). Triethanolamine (TEA) As Flow Improver For Heavy Crude Oils IOSR Journal of Applied Chemistry (IOSR-JAC) e-ISSN: 22785736. Volume 8, Issue 3 Ver. I. (Mar. 2015), PP 3438

28. Carnahan N.F.(1989) Paraffin deposition in petroleum production. J. Petrol. Technol. 41 (10) (1989) 1024-1025.

29. D. Chandaa, A. Sarmaha, A. BorthakuraR(1998), K.V. Raoa, B. Subrahmanyama and H.C. Dash Combined effect of asphaltenes and flow improvers on the rheological behaviour of Indian waxy crude oil Fuel Vol. 77, No. 11, pp. 1163-1167, 199801998 Elsevier Science Ltd. All rights reserved
PII: SO016-2361(98)00029-S Printed in Great Britain 0016.2361/98

30. E. M. Newberry (1984), Chemical effects on crude oil pipeline pressure problems,Journal of Petroleum Technology, vol. 36,pp. 779-786, 1984.

31. E. M. Newberry(1984) Chemical effects on crude oil pipeline pressure problems, Journal of Petroleum Technology, vol. 36,pp. 779-786, 1984.

32. Eid M. S. Azzam , Sayed A. Ahmed, Hanafy Mhmoud Abd El-salam, Elshafie Ahmed Mahmoud $\operatorname{Gad}(2018)$ Synthesis and characterization of $\mathbf{N}$ alkyl-2-aminopyridinum oligomers as pour point depressants for crude oil. Egyptian Journal of Petroleum · October 2018

33. El-Gamal IM, Atta AM, Al-Sabbagh AM(1997). Polymeric structures as cold flow improvers for waxy residual fuel oil. Fuel 1997;76(14-15):14718.

34. Enas A.Ismail, Hussin I.Al-Shafey, R.S.Abdel Hameed, O.E.El Azabawy(2014).Effect of hetero atoms on crystal wax structures modification for Egyptian waxy crude oils MSAIJ, 10(9), 2014 [355362]

35. F.M.Ghuiba, T.T.Khidr, S.A.Mahmoud (2014). Preparation and evaluation of some surfactants as pour point depressants in oil field CTAIJ, 9(2) 2014

36. Francois Rullens, Michel Devillers, Andre Laschewsky (2005) A Regular, Hydrophobically Modified Polyampholyte as Novel Pour Point Depressant (C) 2005 Wiley Periodicals, Inc. J Appl Polym Sci 98: 2101-2108, 2005Sarkyt E. Kudaibergenov, Alexander G. Didukh, Zhanar E. Ibraeva, Larisa A. Bimendina,

37. Frohlich, A., and Rice, B. (2005). Evaluation of camelina sativa oil as a feedstock for biodiesel production. Ind. Crops Prod. 21(1):25-31.

38. Fusheng Zhang, Baoshan Guan, Guoliang Liu, Xuening Li, Zhuoyan Zhu and Huimin Su.(2018) Application and Challenge of Flow Improver for the Development of Heavy Oil and Waxy Crude In The Second International Conference on Materials Chemistry and Environmental Protection (MEEP 2018), pages 77-82 ISBN: 978-989-758-360-5 Copyright c 2019 by SCITEPRESS - Science and Technology Publications, Lda. All rights reserved

39. Fusheng Zhang, Huizhuan Xie, Lijian Dong (2001), A STUDY ON BEM SERIES OF POUR POINT DEPRESSANTS AND THEIR APPLICATION IN CHINA Oilfield Chemistry Dept. of Research Institute of Petroleum E \&D, CNPC Copyright 2001, Society of Petroleum Engineers Inc.

40. Gang Chen, Ying Tang and Jie Zhang (2011). Synthesis and application of polyaminoamide as new paraffin inhibitor from vegetable oil (C) 2011 Chen et al; licensee BioMed Central Ltd.

41. Ghosh P and Das T (2014) Synthesis and Characterization of Homopolymer of Decyl 
Acrylate and its Copolymer with Styrene and Evaluation of their Performance as a Pour Point Depressant in Lubricating Oil. Petroleum Science and Technology 32(12): 1448-1457.

42. Girma T. Chala, Shaharin A. Sulaiman, Azuraien Japper-Jaafar (2018), Flow start-up and transportation of waxy crude oil in pipelines-A review, Journal of Non-Newtonian Fluid Mechanics 251 (2018) 69-87

43. Guo, X., Pethica, B. A., Huang, J. S., Adamson, D. H., and Prud'homme, R. K. (2006). Effect of cooling rate on crystallization of model waxy oils with microcrystalline poly (ethylene butane). Energy Fuels 20: 250-256.

44. H. S. El-Sheshtawy and T. T. Khidr(2016), Some biosurfactants used as pour point depressant for waxy egyptian crude oil PETROLEUM SCIENCE AND TECHNOLOGY 2016, VOL, 34, NO, 16, 1475-1482

45. H.I.Al-Shafey, R.S.Abdel Hameed, E.A.Ismail, O.E.El Azabawy (2014).Studies of poly ethylene acrylic acid derivatives as pour point depressants of waxy crude oils. OCAIJ, 10(8), 2014 [308-314]

46. Hamdi H. Abou El Naga, Wedad M. Abd El Azim and Mohamed M. Ahmed (1985), Polymeric Additives for Pour Point Depression of Residual Fuel Oils J. Chem. Tech. Biotechnol. 1985, 35A, 241-247

47. Hemant P. Soni and Dinakar P. Bharambe (2006). Synthesis and Evaluation of Polymeric Additives as Flow Improvers for Indian Crude Oil Iranian Polymer Journal 15 (12), 2006, 943-954

48. Henry S. Ashbaugh, Lewis J. Fetters, Douglas H. Adamson, and Robert K. Prud'homme (2002)Flow improvement of waxy oils mediated by selfaggregating partially crystallizable diblock copolymers $\odot 2002$ by The Society of Rheology, Inc.J. Rheol. 46 (4), 763-776 July/August 2002

49. Huang, Z. Y., Lee, H. S., Senra, M., and Fogler, H. S. (2011). A fundamental model of wax deposition in Subsea oil pipelines. Am. Inst. Chem. Eng. J. 57:2955-2964.

50. I. M. El-Gamal, A. M. Atta and A. M. AlSabbagh(1997). Polymeric structures as cold flow improvers for waxy residual fuel oil Fuel 1997 Volume 76 Number 14115

51. Jack F. Tinsley, Justin P. Jahnke, Douglas H. Adamson, Xuhong Guo, Devang Amin, Robert Kriegel, Rajesh Saini, Heather D. Dettman, and Robert K. Prud'home (2009), Waxy Gels with Asphaltenes 2: Use of Wax Control Polymers () 2009 American Chemical Society Published on Web 03/19/2009

52. Johnston, R.L., Lauzon, P.A. and Pierce, J.D. (2009). Increasing Heavy Crude Oil flow through a New Flow Improver Product - A case study. A report by Conocophillips Specialty Products Inc.
53. Jorda MR.(1966) Paraffin deposition and prevention in oil wells. $\mathrm{J}$ Petrol Technol 1966(December):1605-12.

54. Jun Xu, Huiqin Qian, Shili Xing, Li Li, and Xuhong Guo (2010) Synthesis of Poly(maleic acid alkylamide-co-r-olefin-co-styrene) Co-polymers and Their Effect on the Yield Stress and Morphology of Waxy Gels with Asphaltenes (C2010 American Chemical Society

55. Jun Xu, Xingyu Zhang, Jie Sun, Li Li, and Xuhong Guo1 (2009),How comb-type poly(maleic acid alkylamide-co- $\alpha$-olefin) assemble in waxy oils and improve flowing ability @ 2009 Curtin University of Technology and John Wiley \& Sons, Ltd.

56. Kun Cao,Xiang-xia Wei,Ben-ju Li, Jiang-shan Zhang, and Zhen Yao (2012), Study of the Influence of Imidization Degree of Poly(styrene-co-octadecyl maleimide) as Waxy Crude Oil Flow Improvers (C) 2012 American Chemical Society

57. Lang, S., and Philp, J. C. (1998). Surface active lipids in Rhodococci. Antonie Van Leeuwenhoek 74:59-70.

58. Laura V. Castro and Flavio Vazquez (2008). Copolymers as Flow Improvers for Mexican Crude Oils 2008 American Chemical Society Published on Web 10/08/2008

59. Laura V. Castro, Eugenio A. Flores, §and Flavio Vazquez(2011).Terpolymers as Flow Improvers for Mexican Crude Oils @2011 American Chemical Society

60. Li Li, Xuhong Guo,,Douglas H. Adamson, Brian A. Pethica, John S. Huang, and Robert K. Prud'homme (2010), Flow Improvement of Waxy Oils by Modulating Long-Chain Paraffin Crystallization with Comb Polymers: An Observation by X-ray Diffraction 10.1021/ie101575w @ C 2011 American Chemical Society Published on Web 11/30/2010

61. Li, P. J., Zhang, S., He, Y. T.,( 1990). Classification of crude oil. Oil \& Gas Storage and Transportation, 9(1):74-77.

62. Liao Ke-Jian \& Liu Guo-Min (2007), PSM as pour point depressant for diesel Department of Applied Chemistry, Fushun Petroleum Institute Fushun, Liaoning, 113001, P.R.China Published online: 16 May 2007.

63. Long Fang, Xiaodong Zhang, Jinhai Ma, and Botao Zhang (2012). Investigation into a Pour Point Depressant for Shengli Crude Oil Ind. Eng. Chem. Res. 2012, 51, 11605-11612

64. Mahto, V.; Verma, D.; Singh, H.(2010) Kinetic study of wax deposition in the flow lines due to Indian crude oil. In Proceedings of the First International Conference on Drilling Technology, IIT Madras, Chennai, India, Nov. 18-21, 2010.

65. Mayur R. Patel, Pranav S. Chitte, D.P. Bharambe (2016) Oleic acid based polymeric flow improvers for Langhnaj (North Gujarat, India) crude oil 1110-0621 _ 2016 Production and hosting by 
Elsevier B.V. on behalf of Egyptian Petroleum Research Institute.

66. Misra S., Baruah S., Singh K.(1995) Paraffin problems in crude oil production and transportation, SPE., 28181, 50-54, 1995.

67. Mrs. Prabha Modi, Mr. Parth Modi, Zarna Patel, Dr. Ashish Nagar (2020). An overview of different pour point deppresant synthesized and their behaviour on different crude oils (C) 2020 IJCRT | Volume 8, Issue 8 August 2020 | ISSN: 2320-2882

68. Mulligan, C. N., Yong, R.N., and Gibbs, B. F. (2001). Surfactant-enhanced remediation of contaminated soil: a review. Rev.Eng. Geol. 60:371-380.

69. Odutola TO, Idemili CA (2020) Effect of poly (ethylene butene) and nano aluminum oxide blend on the viscosity of Nigerian crude oil. J Pet Explor Prod Technol 10:2531-2539

70. Okoliegbe, I.N., and Agarry, O. O. (2012). Application of microbial surfactant (a review). Scholarly J. Biotechnol. 1:15-23.

71. Olusegun Peter Akinyemia, Joseph Denis Udonne, Vincent Enontiemonria Efeovbokhan, Ayodeji Ayodele Ayoola (2016) A study on the use of plant seed oils, triethanolamine and xylene as flowimprovers of Nigerian waxy crude oilO.P. Akinyemi et al. / Journal of Applied Research and Technology xxx (2016) xxx-xxx

72. P. Kriz, S.I. Andersen (2005) Effect of Asphaltenes on Crude Oil Wax Crystallization Energy Fuels 19 (2005) 948.

73. Qiang DENG, Yun BAI, Xue-Fan GU,a, Gang CHEN, Zhi-Fang ZHANG(2016).Synthesis of PolyHydrazide from Canola Oil and Use as Flow Improver for Crude Oil. Copyright (C) 2016, the Authors. Published by Atlantis Press.

74. R. Hoffmann and L. Amundsen (2013), Influence of wax inhibitor on fluid and deposit properties, Journal of Petroleum Science and Engineering, vol. 107, pp. 12-17, 2013.

75. Rafael M.P., María de Lourdes M., Beatriz Z.R.(2011) Transportation of heavy and extraheavy crude oil by pipeline: A review. J. Petrol. Sci. \& Eng. 75 (2011) 274-282.

76. Ragunathan T, Husin H, Wood CD (2020) Effect of crude palm oil and crude palmkernel oil upon wax inhibition. ACS Omega 5(31):19342-19349

77. Rasha A. El-Ghazawy, Reem K. Farag (2010).Synthesis and Characterization of Novel Pour Point Depressants Based on Maleic Anhydride-Alkyl Acrylates Terpolymers @2009 Wiley Periodicals, Inc. J Appl Polym Sci 115: 72-78, 2010

78. Ravindra Kumar, Gauri Sankar Bora , Shirsendu Banerjee, Ajay Mandal Tarun Kumar Naiya (2017) Application of naturally extracted surfactant from Madhuca longifolia to improve the flow properties of heavy crude oil through horizontal pipeline (C) 2017 Published by Elsevier B.V.
79. S. M. Anisuzzaman, Sariah Abang, Awang Bono, D. Krishnaiah, N. M. Ismail, G. B. Sandrison (2017) An Evaluation of Solubility of Wax and Asphaltene in Crude Oil for Improved Flow Properties Using a Copolymer Solubilized in Organic Solvent with an Aromatic Hydrocarbon International Scholarly and Scientific Research \& Innovation 11(10) 2017

80. Sarica C, Panacharoensawad E (2012) Review of paraffin deposition research under multiphase flow conditions. Energy Fuels 26:3968-3978

81. Sharma, S.; Mahto, V.; Sharma V. P. To Study the Effect of Flow Improvers on Indian Waxy Crude Oil. In Proceedings of the Second International Conference on Drilling Technology 2012 (ICDT2012) and First National Symposium on Petroleum Science and Engineering 2012 (NSPSE-2012), Chennai, India, Dec. 6-8, 2012.

82. Shijun Chen, Kang Zhao, Gang Chen, Li Bai,and Lajun Feng (2016) Synthesis and Application of a Spirocompound as Clean Viscosity-Reducer for Crude Oil Hindawi Publishing Corporation Journal of Chemistry Volume 2016, Article ID 3827403,

83. Shivanjali Sharma, Vikas Mahto,* and Virender Parkash Sharma(2014). Effect of Flow Improvers on Rheological and Microscopic Properties of Indian Waxy Crude Oil (c) 2014 American Chemical Society

84. Son A.J., Graugnard R.B., Chai B.J.(1993) The effect of structure on performance of maleic anhydride copolymers as flow improvers of paraffinic crude oil, Proc. SPE. Int. Symp. on Oil Field Chemistry., New Orleans, U.S.A., 25186, 351362, 1993.

85. Soni, H. P., Bharambe, D.P., Nagar, A., and Kiranbala (2005). Synthesis of Chemical Additives and their effect on Akholjuni Crude Oil (Gujarat, India). Indian Journal of Chemical Technology. 12, $55-61$.

86. Srushti Deshmukh, D.P. Bharambe (2007). Synthesis of polymeric pour point depressants for Nada crude oil (Gujarat, India) and its impact on oil rheology (C) 2007 Elsevier B.V. All rights reserved.

87. Sultana Yeasmin, Mainul Hoque and Pranab Ghosh(2018). Synthesis and Characterization of Methacrylate Based Polymeric Additives for Crude Petroleum Oil To Chemistry Journal Vol 1 No 3 (2018) ISSN: 2581-7507

88. Thevaruban Ragunathan , Hazlina Husin , and Colin D. Wood (2020), Wax Formation Mechanisms, Wax Chemical Inhibitors and Factors Affecting Chemical Inhibition Appl. Sci. 2020, 10, 479

89. Tomás Eduardo Chávez-Miyauchi, Luis S. ZamudioRivera, and Victor Barba-López (2013). Aromatic Polyisobutylene Succinimides as Viscosity Reducers with Asphaltene Dispersion Capability for Heavy and Extra-Heavy Crude Oils (C) 2013 American Chemical Society

90. Venkatesan R, Ostlund JA, Chawla H, Wattana P, Nyden M, Fogler HS.(2003) The effect of 
asphaltenes on the gelation of waxy oils. Energy Fuels 2003;17(6):1630-40.

91. Wang LS, Flamberg A, Kikabhai T.(1999) Select the optimum pour point depressant. Hydrocarb Process 1999(February):59-62.

92. Wang W, Huang Q, Liu Y, Sepehrnoori K (2015) Experimental study on the mechanism of wax removal during pipeline pigging. In: SPE annual international conference and exhibition, Texas

93. Wang, B., 1995. Paraffin characteristics of waxy crude oils in china and the methods of paraffin removal and inhibition. International Meeting on PetroleumEngineering, SPE 29954

94. Wangang Zheng, Shujun Wang, Jie Liu, Fanbin Meng, Yanshan Li,Huanqing $\mathrm{Ma}$, and Ting $\mathrm{Li}$ (2014)Synthesis and Evaluation of Wax Dispersant for Diesel () 2014 American Chemical Society

95. William Iheanyi Eke - Sampson Kofi Kyei2 - Joseph Ajienka - Onyewuchi Akaranta(2021). Effect of bio-based flow improver on the microscopic and low-temperature flow properties of waxy crude oil (C) The Author(s) 2021

96. Xu, J., Qian, H., Xing, S., Li, L., and Guo, X. (2011). Synthesis of poly (maleic acid alkylamide-co-rolefin-co-styrene) co-polymers and their effect on the yield stress and morphology of waxy gels with asphaltene. Energy Fuels 25:573-579.

97. Yumin Wu, Guangdi Ni, Fei Yang, Chuanxian Li, and Guoliang Dong (2012). Modified Maleic Anhydride Co-polymers as Pour-Point Depressants and Their Effects on Waxy Crude Oil Rheology. Energy Fuels 2012, 26, 995-1001

98. Z. Chen, X. Wang, H. Zhang, C. Yang, and H. Shan (2014) A Study on the Interaction of Crude Oil Waxes With Polyacrylate Pour Point Depressants by Monte Carlo Simulation Petroleum Science and Technology, 32:2151-2157, 2014 Copyright (C) Taylor \& Francis Group, LLC

99. Rohit Sharma, Barasha Deka, Vikas Mahto, Hari Vuthaluru, Chun-Zhu Li (2019), Investigation into the Flow Assurance of Waxy Crude Oil by Application of Graphene-Based Novel Nanocomposite Pour Point Depressants Journal Contribution posted on 18.11.2019

100. Yousef Al-Roomia, Reena Georgea, Ahmed Elgibalyb, Ali Elkamel (2004),Use of a novel surfactant for improving the transportability/transportation of heavy/viscous crude oils Journal of Petroleum Science and Engineering 42 (2004) 235- 243 